\title{
Article \\ A Novel Hybrid MPPT Technique to Maximize Power Harvesting from PV System under Partial and Complex Partial Shading
}

\author{
Sajid Sarwar ${ }^{1}\left(\mathbb{D}\right.$, Muhammad Yaqoob Javed ${ }^{1}$, Mujtaba Hussain Jaffery ${ }^{1}{ }^{\mathbb{D}}$, Jehangir Arshad ${ }^{1, *} \mathbb{D}^{\mathbb{D}}$, \\ Ateeq Ur Rehman ${ }^{2}\left(\mathbb{D}\right.$, Muhammad Shafiq ${ }^{3, *(\mathbb{D})}$ and Jin-Ghoo Choi ${ }^{3, *(\mathbb{D})}$ \\ 1 Department of Electrical and Computer Engineering, COMSATS University Islamabad, \\ Lahore 54000, Pakistan; engrsajidsarwar@gmail.com (S.S.); Yaqoob.javed@ucp.edu.pk (M.Y.J.); \\ m.jaffery@cuilahore.edu.pk (M.H.J.) \\ 2 Department of Electrical Engineering, Government College University, Lahore 54000, Pakistan; \\ ateqrehman@gmail.com \\ 3 Department of Information and Communication Engineering, Yeungnam University, \\ Gyeongsan 38541, Korea \\ * Correspondence: jehangirarshad@cuilahore.edu.pk (J.A.); shafiq@ynu.ac.kr (M.S.); jchoi@yu.ac.kr (J.-G.C.)
}

check for updates

Citation: Sarwar, S.; Javed, M.Y; Jaffery, M.H.; Arshad, J.; Ur Rehman, A.; Shafiq, M.; Choi, J.-G. A Novel Hybrid MPPT Technique to Maximize Power Harvesting from PV System under Partial and Complex Partial Shading. Appl. Sci. 2022, 12, 587. https://doi.org/10.3390/ app12020587

Academic Editor: Tomonobu Senjyu

Received: 7 November 2021

Accepted: 24 December 2021

Published: 7 January 2022

Publisher's Note: MDPI stays neutral with regard to jurisdictional claims in published maps and institutional affiliations.

Copyright: (c) 2022 by the authors. Licensee MDPI, Basel, Switzerland. This article is an open access article distributed under the terms and conditions of the Creative Commons Attribution (CC BY) license (https:// creativecommons.org/licenses/by/ $4.0 /)$.

\begin{abstract}
Photovoltaic (PV) system has been extensively used over the last few years because it is a noise-free, clean, and environmentally friendly source of energy. Maximum Power Point (MPP) from the PV energy systems is a challenging task under modules mismatching and partial shading. Up till now, various MPP tracking algorithms have been used for solar PV energy systems. Classical algorithms are simple, fast, and useful in quick tracing the MPP, but restricted to uniform weather conditions. Moreover, these algorithms do not search the Global Maxima (GM) and get stuck on Local Maxima (LM). However, bio-inspired algorithms help find the GM but their main drawback is that they take more time to track the GM. This paper addresses the issue by using the combination of conventional Incremental Conductance ( $\mathrm{InC}$ ) with variable step size and bio-inspired Dragonfly Optimization (DFO) algorithms leading to a hybrid (InC-DFO) technique under multiple weather conditions, for instance, Uniform Irradiance (UI), Partial Shading (PS), and Complex Partial Shading (CPS). To check the robustness of the proposed algorithm, a comparative analysis is done with six already implemented techniques. The results indicate that the proposed technique is simple, efficient with a quicker power tracking capability. Furthermore, it reduces undesired oscillation around the MPP especially, under PS and CPS conditions. The proposed algorithm has the highest efficiencies of 99.93\%, 99.88\%, 99.92\%, and 99.98\% for UI, PS1, PS2, and CPS accordingly among all techniques. It has also reduced the settling time of $0.75 \mathrm{~s}$ even in the case of the CPS condition. The performance of the suggested method is also verified using real-time data from the Beijing database.
\end{abstract}

Keywords: ant colony optimization; complex partial shading; cuckoo search; dragonfly optimization; fruit fly optimization; incremental conductance; maximum power point

\section{Introduction}

The demand for Electrical energy is increasing over time. Thus, the consumption of fossil fuels is also growing rapidly and their results greatly affect the environment, for instance, in terms of fossil fuel produces Carbon and Sulphur dioxide which causes the greenhouse effect. Presently, Renewable Energy Resources (RES) are playing a significant role in substituting the traditional energy resources of fossil fuel. Thus, many countries are switching to RES e.g., Iceland, Sweden, the U.S., Costa Rica, and Nicaragua. In the previous decade among all RES, solar energy has emerged as a promising source of energy and has gained more attention because it is a noise-free, pollution-free, increasingly cost-effective, and limitless source of energy. In the coming years based on recent advancements in solar 
technologies, PV energy has brought significant development in the solar PV market as it is expecting to surpass other RES as well.

PV systems, on the other hand, have faced a number of issues, one of which is maximizing efficiency under varying irradiance circumstances. Characteristic curves of I-V \& P-V of a photovoltaic system by nature are non-linear due to the changing nature of the sun, manufacturing tolerance, aging, shadowing, bird dropping and different orientations of the Solar cells to the sun rays [1]. The non-linear behavior of the PV system is a result of partial shading [2]. As a result, maximum power point tracking (MPPT) has emerged as the primary problem for PV systems.

By changing the duty cycle of the DC-DC converter, the problem of the partial shading is resolved with the capability to track MPPT. Many local maxima (LM) and single GM are visible on the PV and I-V characteristics curves of PV energy systems. To obtain the desired optimization, the pulse signal of the DC-DC converter is required to be controlled by a power switch.

Whenever the PV array is exposed to uniform irradiance, almost every algorithm works well; but, when the PV module is partially shaded, its performance deteriorates. Many researchers have looked into extracting the full output power from shaded PV modules, using various integrated power typologies for both offline and online grid connecting PV energy systems [3].

Different Perturb \& Observe (P\&O) and Incremental Conductance ( $\operatorname{InC})$ Maximum power point (MPP) techniques have been used in the PV system by the researcher. For detecting the GM, P-V \& I-V curves are used. The techniques used in [4] are evaluated based on speed, accuracy, and complexity. Fractional Short Circuit Current (FSCC), P\&O, Fractional Open Circuit Voltage (FOCV), and InC techniques are conventional and most commonly employed techniques in PV energy systems [5].

FOCV method is easy to implement as it uses only one feedback loop. InC can use analog devices instead of digital components i.e microcontrollers. To update the open-circuit voltage, the output of PV modules needs to be opened frequently [6]. This algorithm offers low efficiency due to the expected error in $K_{o c}$ and power loss during the measurement of $V_{o c}$. Due to the use of approximate values for the correlation between $V_{o c}$ and $V_{m p p}$, this method is incapable to choose the real MPP values.

To get FSCC, the PV array needs to be shorted for a small interval of time using an additional switch which makes this technique more troublesome as compared to the FOCV method. Like the FOCV method, this technique cannot track real MPP due to approximations. To overcome this problem, the photovoltaic voltage sweeping process is proposed to attain real MPP. So, it will obscure the system that increase the overall system cost [7]. The algorithm must be calibrated first, so $V_{1}$ is adjusted to $0.05 V_{o c}$ and $V_{2}$ is configured to $0.95 V_{o c}$, so the MPP is between $5 \%$ to $95 \%$ of $V_{o c}$, where $V_{o c}$ is the open-circuit voltage under standard testing conditions (STC) [8].

From the conventional MPPT techniques, the $\mathrm{P} \& \mathrm{O}$ method perturbs the voltages and observes the power of the system. If the previous power is less than the new power, the homogeneous process of power perturbation is repeated for locating the MPP. Otherwise, it will reverse the perturbation process for tracking MPP. The major disadvantage of $\mathrm{P} \& \mathrm{O}$ is the oscillation of the system around MPP which results in energy loss that's why this method is not suitable for varying weather conditions. Reference voltage that has a small step size and precise duty cycle can compensate for these issues.

To compensate for the problems of $\mathrm{P} \& \mathrm{O}$, adaptive $\mathrm{P} \& \mathrm{O}$ techniques with changing step size are proposed in the literature [9]. Based on the position of the switching point, changing pulse signal techniques settles the step size of the DC to DC converter. When the MPP is far from the position of the operating point then a larger step size is employed. The size of the pulse signal decreases whenever it is located nearer to MPP. So, at MPP step size can decrease to zero.

An improved effective hybrid MPPT of PV combines the modified enhanced PSO and P\&O. To minimize the area between the P-V curves, the Search Skip Judge (SSJ) 
Mechanism is incorporated. In this way, the unneeded motion of the particle is reduced causing fast convergence. An initial form of the SSJ proposed algorithm is evaluated in comparison with widely known MPPT algorithms i.e., modified InC, hybrid PSO, and modified CS. The effectiveness of these techniques are analyzed based on searching several required computation cycles, global maximum power point correctly, tracking time, and the scanned interval. Results demonstrate that the proposed technique significantly increases the accuracy and speed of finding the real global maximum power point. Moreover, it is irrespective of the complexity of PS conditions [10].

In [11], the authors describe the analysis of PS conditions for PV energy systems. In a PV energy system during partial shading conditions, if the PV modules increase in a string, then the $0.8 V_{o c}$ model is used to raise the efficiency. Peaks in the case of PS are situated at the multiples of $0.8 V_{o c}$. For finding the correct position of peaks in the PV energy system for partial shading conditions, the authors [11] used a set of new equations model. Problems of partial shading in long-term PV systems are resolved using a model. However, this model slows the speed of the overall PV system.

Using the three-point-based method, the authors in [12] examine the parameters extraction of a single diode model. The pivot point is used to make points of critical data. The model forces to pass through these points after that Evolutionary Algorithm (EA) is applied to fine-tune the remaining section of the suitable curve. The EA technique shows substantial enhancement for fitting accuracy. From the MATLAB/Simulink results, it is concluded that the suggested method constantly converges to an optimum solution in less than 50 iterations but increases the system complexity [12].

The authors in [7] also proposed many techniques based on artificial intelligence like neural networks \& fuzzy logic control. In the Artificial Neural Network (ANN), the input combination is considered as the surrounding condition of PV parameters, and output is assumed to be either reference voltage or duty cycle. As compared to the conventional neural network (NN) technique for MPPT, a multi-level neuro-fuzzy model has been proposed. The proposed model has been proven better efficient under a wide range of operating circumstances [13]. However, as the characteristic of PV array changes, the system needs to train periodically to obtain high accuracy [14].

The main benefits of Fuzzy Logic Control (FLC) is the acceptance of the noisy input signal and its ability to converge during a sudden change in surrounding conditions $[15,16]$. However, this technique determined the error based on a rule base table. The drawback of this method is that it highly depends on the availability of previous knowledge of the input signal [7]. In the literature, the Takagi-Sugeno model is used for further improvement in the stability and robustness of the system [17,18].

State-Space (SS) based MPPT technique uses the SS model to represent PV systems and dynamic feedback controllers to track MPP. Due to the ease of change in system parameters, this technique is very suitable even in fast-changing weather conditions and partially shaded conditions. However, no experimental verification is given $[19,20]$. The Slide Control Method (SCM) is achieving MPP that achieved the control of DC/DC converters. This technique normally employs the hysteric mode control of the DC/DC converter. The leading advantage of this method is its dynamic response and fast speed. Although, the unstable switching frequency is its major drawback [21].

Another MPP Flower Pollination Algorithm (FPA) has been introduced by the researchers in which five pollens or duty cycles are initially generated with an FPA between $0-1$ and measure the power of each pollen. The pollen that gives the maximum power is chosen as the best power. To deciding which pollen will pass through global pollination or local pollination, a new number between $0-1$ is randomly generated that has a 0.8 switching probability " $\mathrm{P}$ " for achieving the power. Researchers concluded that the best power gives the global best value after 25 iterations only [22]. The major disadvantages of FPA are high computation time, difficulty to tune parameters, complex structure, and procedural complications [23]. 
Modified FPA is described for the MPP of the PV system. The performance of the system is improved but the structure of FPA has become more complex [24]. Anderson et al. [25], examined the MPP using global optimization issues known as Random Search Method (RSM) as it tracks the MPP using a random solution. In defined limits, Anderson et al. produce the solution randomly and search for appropriate solutions that have a range between $0-1$. To measure the power, these values send to the DC-DC converter against each input. Furthermore, these values are restructured continuously until the MPP is obtained after each iteration.

In [26] a Modified Firefly algorithm (FA) for the calculation of MPP is elaborated. To decrease the randomization of fireflies, randomization $\alpha$ and $\beta$ parameters are introduced by varying irradiance and temperature. From the result, the authors of [26] concluded that efficiency and tracking speed is improved as compared to the conventional FA.

The bypass diodes are reverse biased and have little effect under UI levels. Whenever the PV array is partially shaded, the bypass diode is forward biased, and the current flows via the diode instead of through the PV module. Many MPP's occur in the P-V curve under partial shading due to the existence of bypass diodes. Traditional MPPT algorithms are looking for the peak of the P-V curve centered on a localized initial stage. As a result, they are unable to distinguish between LMPP and GMPP $[27,28]$.

The authors in [29] improved the modified FA in terms of searching speed and decreases the number of computations of conventional FA. A Simplified FA is elaborated in which decreases the computational load and rises the MPPT in the PV energy systems. Steady-state oscillations also reduce additionally. Many other optimization techniques for MPP in PV systems such as Artificial Bee Colony (ABC) [30], Ant Colony Optimization (ACO) [31], Bacterial Fragmentation and aging (BFA) [32], Genetic Algorithm (GA) [33], Differential Evaluation (DE) [34], Grey Wolf Optimization (GWO) [35] and Simulated Annealing (SA) [36] algorithms have been discussed and evaluated based on response time, accuracy, efficiency, partial shading, and performance of the PV system under rapid response.

Up till now, under all circumstances, no technique gave the best results in terms of convergence and settling time, power tracking capability, and efficiency. There is still exists a research gap that how the PV system gives the response and addresses the PS condition according to the system requirements. These gaps still required to be eliminated by hybridizing the two techniques. So, We hybridize the conventional InC and softcomputing DFO techniques and use their advantages. If the uniform condition occurs then there is no benefit of using the soft computing techniques because they are slow with respect to change in any environmental condition. In the majority of cases, there is no existing PS condition and system response uniformly. However, if the PS does not occur in the PV system then InC is an ideal technique for use. In the world mostly P\&O and InC techniques are used because they are fast and simple but cannot address the PS and CPS. On the other hand, a research gap exists in soft computing techniques where some tackle the PS condition and cannot respond to the CPS condition. Our contribution in this paper is as follows:

- A hybrid MPP tracking technique is implemented using InC and DFO to minimize tracking time and improve accuracy.

- A mathematical model is implemented to detect the UI, PS, and especially CPS condition in a PV system.

- $\quad$ Five different cases are developed to identify the accuracy and response time of the proposed technique.

- $\quad$ To check the robustness of the proposed Hybrid technique by comparing it with six previous implemented techniques i.e., FA, InC, ACO, DFO, PSO, and CS.

- The performance of the suggested method is also verified using real-time data from the Beijing database.

The rest of the paper is arranged in the following Sections. Section 2 described the partially shaded PV energy system. Sections 3 and 4 elaborate on the previous and proposed MPPT techniques for PV energy systems. Section 5 presented the simulation 
model. In Section 6 results and discussion are illustrated for all weather conditions. Finally, the conclusion of the paper is given in Section 7.

\section{Description of the Partially Shaded PV Energy System}

\subsection{Description of the Power and Control Circuits}

Ideally, whenever light hits the photovoltaic cell, it behaves similarly to a current source and is connected with a parallel diode. A PV module's characteristics may be acquired through an ideal model of a single diode. Practically, a single diode model consists of parallel and series resistance named as $R_{p}$ and $R_{s}$ respectively.The schematic diagram of a single diode model of PV is demonstrated in Figure 1.

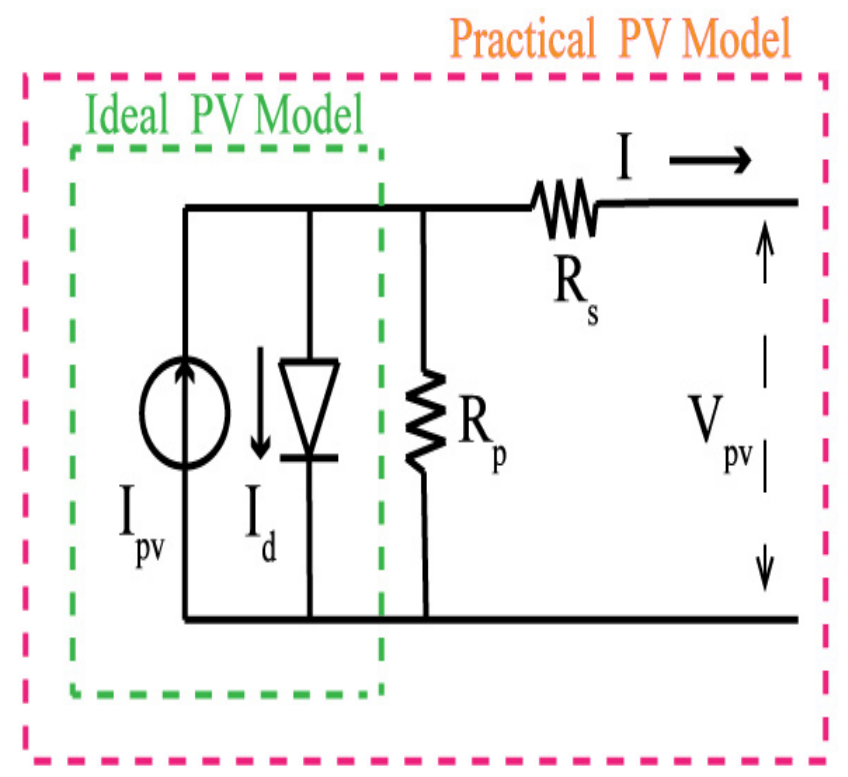

Figure 1. Single diode PV model.

However, in PV cell's single diode practical model, $R_{p}$ and $R_{S}$ shows the losses. By using Kirchhoff's current law (KCL), mathematical equations of this model are the following:

$$
I=I_{p v}-I_{d}-I_{s h}
$$

where the values of $I_{d}$ and $I_{s h}$ are represented below in (2) and (3):

$$
\begin{gathered}
I_{d}=I_{o}\left[\exp \left(\frac{V+I R_{s}}{n V_{T}}\right)-1\right] \\
I_{s h}=\frac{\left(V+I R_{s}\right)}{R_{s h}}
\end{gathered}
$$

where reverse saturation current is denoted by $I_{o}$. The value of $V_{T}$ is equal to

$$
V_{T}=\frac{N_{s} A K T}{q}
$$

diode's ideality factor is presented by $N_{s}$, ' $K$ ' stands for Boltzmann constant and ' $T$ ' is expressed as the temperature of the photovoltaic cell.

The complete governing equation of a PV cell and its output current (I) is shown by

$$
I=I_{p v}-I_{o}\left[\exp \left(\frac{V+I R_{s}}{n V_{T}}\right)-1\right]-\frac{\left(V+I R_{s}\right)}{R_{s h}}
$$


DC-DC converter in PV energy systems is an integral part of the output power. There are several converters commonly used in a PV system to modify the value of output power like a buck, boost, and buck-boost converter. They decrease or increase the value of voltages according to the system requirements. Among all the other DC to DC converters, the boost converter has the advantages in terms of voltages regulation, power, and efficiency to achieve the desired results. PV energy system's output voltages should be controlled, varying the value of duty cycle of a DC-DC boost converter. For achieving this, the output voltage and connected load must be synchronized. Figure 2 presents the basic schematic diagram of the DC to DC boost converter.

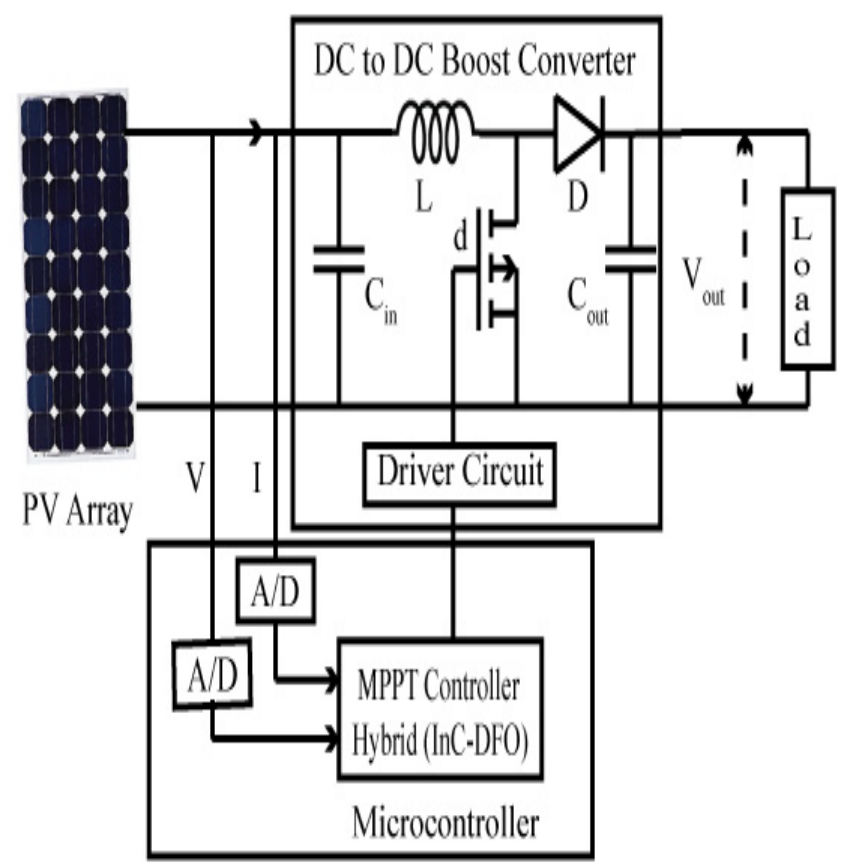

Figure 2. DC to DC Boost-Converter In PV system.

Initially, the reference voltage $\left(V_{r e f r}\right)$ at GM of the PV system is adjusted then the value of $V_{\text {refr }}$ of the boost converter is modulated to modify PV voltage as a reference voltage. The value of the duty cycle is taken from 0 to 1 . The maximum energy can be harvested from the PV energy system by implementing the control algorithm in a microcontroller having zero oscillation. The mathematical equations of output capacitance, duty cycle, input capacitance, output voltage, and inductance of the boost converter are represented below in (6)-(10).

$$
\begin{gathered}
C_{\text {input }}=\frac{\Delta I_{\text {ripple }}}{8 \Delta V_{\text {ripple,pv }} f_{\text {switching }}} \\
D C=\frac{T_{\text {on }}}{T_{\text {switching }}} \\
C_{\text {output }}=\frac{I_{0}}{f_{\text {switching }} 8 \Delta V_{\text {ripple, load }}} \\
V_{\text {out }}=\frac{V_{\text {in }}}{1-D C} \\
L=\frac{D C I_{O}}{2 f_{\text {switching }} \Delta I_{\text {Load }}}
\end{gathered}
$$

where $V_{\text {in }}$ is the input voltage, $f_{\text {switching }}$ represents the switching frequency, $I_{\text {ripple }}$ denotes the ripple current and DC elaborates the duty cycle of a DC-DC boost converter. In PV systems conventional techniques may be stuck on LM and do not achieve GM for maximum 
energy harvesting. Due to this reason, bio-inspired techniques are used in this research for searching the MPP.

\subsection{Description of UI, PS, and CPS under Study}

Uniform irradiance case has the same irradiance values on the PV panels. In the partially shaded condition, it observes the various irradiance level. Due to the PS, a series of PV modules linked together may experience a low current and do not give high efficiency. Many PV modules are connected in series to increase voltages and it is called a string. Multiple strings are connected with a single inverter.

However, due to different irradiance levels, it may result in the non-uniform current that causes the mismatching and hot-spot effects. These effects can be reduced by connecting a bypass diode that gives an extra path to the flow of the high current of other PV modules. PV array of $4 \times 1$ of same and different irradiance levels is shown in Figure $3 a, b$ respectively. PS faces the problem of MPPT that results in low efficiency of PV energy system. This problem is solved by conventional algorithms such as $\mathrm{P} \& \mathrm{O}$ and InC as their decisions are based on negative and positive gradients [5]. These techniques may not find any difference between a single GM and LM that operates on one point only. However, PS produces more than one peak on the curve, and in this way, by using these conventional algorithms the performance is compromised. Bio-inspired algorithms can locate GM successfully for PV energy systems.

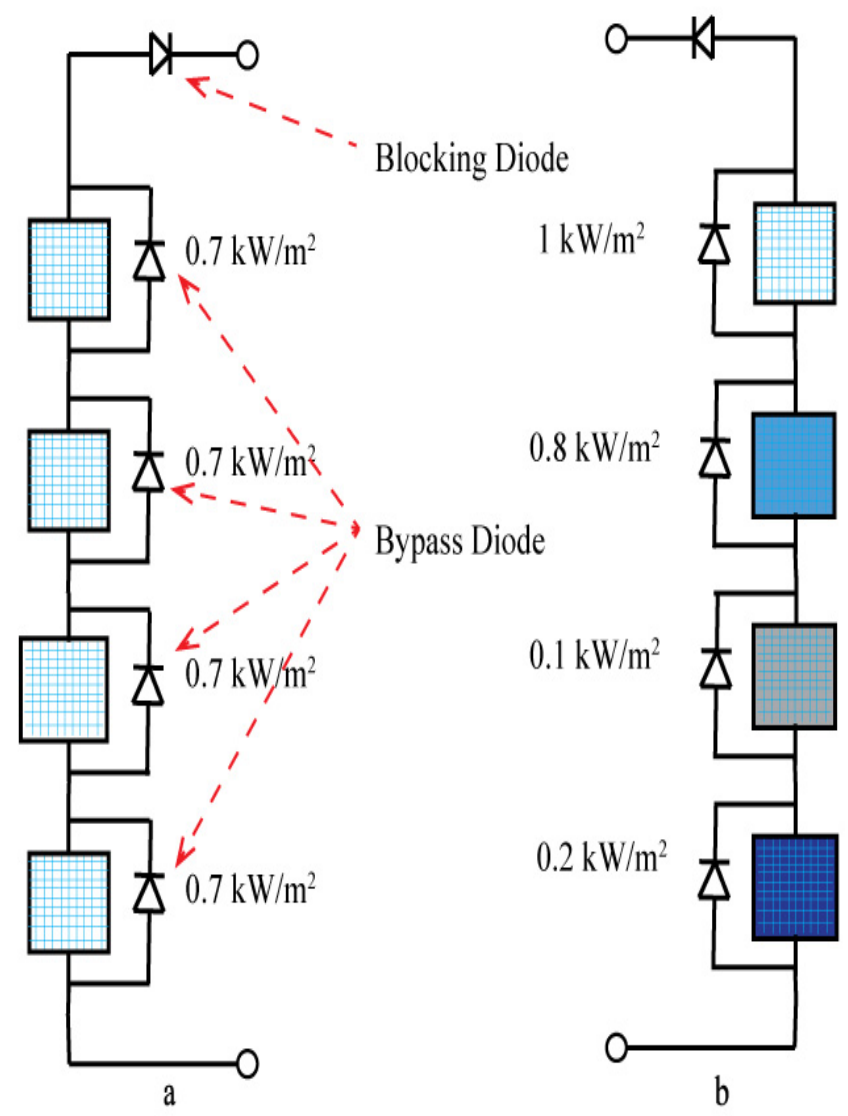

Figure 3. (a) Uniform Irradiance Case (b) Partial Shading Case.

Whenever PV modules in large numbers are combined in series and give the output power, then CPS takes place [10]. Multiple close peaks are found on the P-V and I-V characteristics curves. The collection of these number of different peaks on power and voltage curves is known as a cluster. The CPS block diagram is demonstrated in Figure 4. 


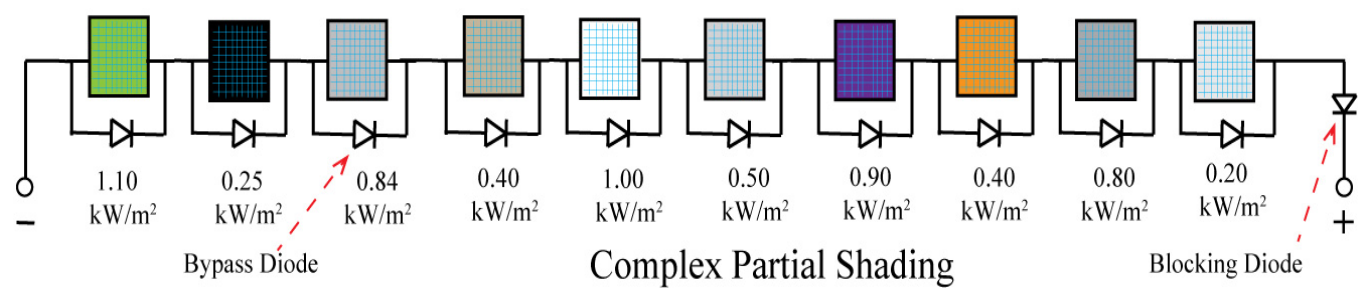

Figure 4. Complex Partial Shading Case.

There is a single GM in all clusters of CPS cases. This single maximum is also known as cluster head maxima. However, in a string, the number of partially shaded PV modules have an equal number of peaks obtained on a PV curve from the PV energy system. P-V characteristics curve of unique type is shown if the shading of the PV energy systems is broadly distributed. Moreover, this curve has multiple close peaks points. In CPS, finding $\mathrm{GM}$ is a big problem.

\section{Previous MPPT Techniques for PV Energy System}

\subsection{Incremental Conductance (InC) Technique}

First, the InC method finds the slope of conduction then changes the duty cycle of the converter. This algorithm works for slope values. A duty cycle of converter rises only for positive slope values and declines for others. It will repeat the same process until found the MPP is on the curve [37] The MPP of the PV array is determined when the derivative of Power by voltage is equal to zero. Basic equations of InC that are used are given as follow:

$$
\frac{\operatorname{dev} P}{\operatorname{dev} V}=0
$$

Equation (11) can be write down as:

$$
\begin{gathered}
\frac{d e v P}{d e v V}=\frac{d e v(I V)}{d e v V}=I+V \frac{d e v I}{d e v V}=0 \\
\frac{d e v I}{d e v V}<-\frac{1}{V} \quad \text { at right of } M P P \\
\frac{d e v I}{d e v V}>-\frac{1}{V} \quad \text { at left of MPP } \\
\frac{d e v I}{d e v V}=-\frac{1}{V} \quad \text { at MPP }
\end{gathered}
$$

Therefore, the authors of [38] proposed a permitted error of approximately $=0.002$, to eliminate the steady-state error. Due to the complexity, the convergence speed of the overall system decreases, and the cost of the system increase [39].

\subsection{Dragon Fly Optimization (DFO) Technique}

DFO is also a bio-inspired algorithm. Around the world, 3000 different species of dragonfly exist. Adult and nymph are the two milestones of a dragonfly's lifecycle. In life, DF spends their most of time in the nymph. During the metamorphism process, they become adults. Dragonfly examines small predators that hunt all the other species of insects. They have rare and unique swarming behavior. There are two main purposes of the DF swarm; the first is hunting and the second is migration. Migration and hunting are also known as dynamic and static swarms. In a static swarm, DF makes a small group over a small area and fly in back and forth motion to hunt the other species of flying prey e.g., mosquitoes and butterflies. Static swarms have two important characteristics named abrupt changes and local movements. On the other hand, in the dynamics swarm, a massive number of DF's make the group for migration from one place to another place. These are the two main behaviors for the inspiration of using the DF technique. These 
two behaviors are very similar to meta-heuristics two-phase such as exploitation and exploration. The primitive pattern of DFO is shown in Figure 5 in between the individuals.

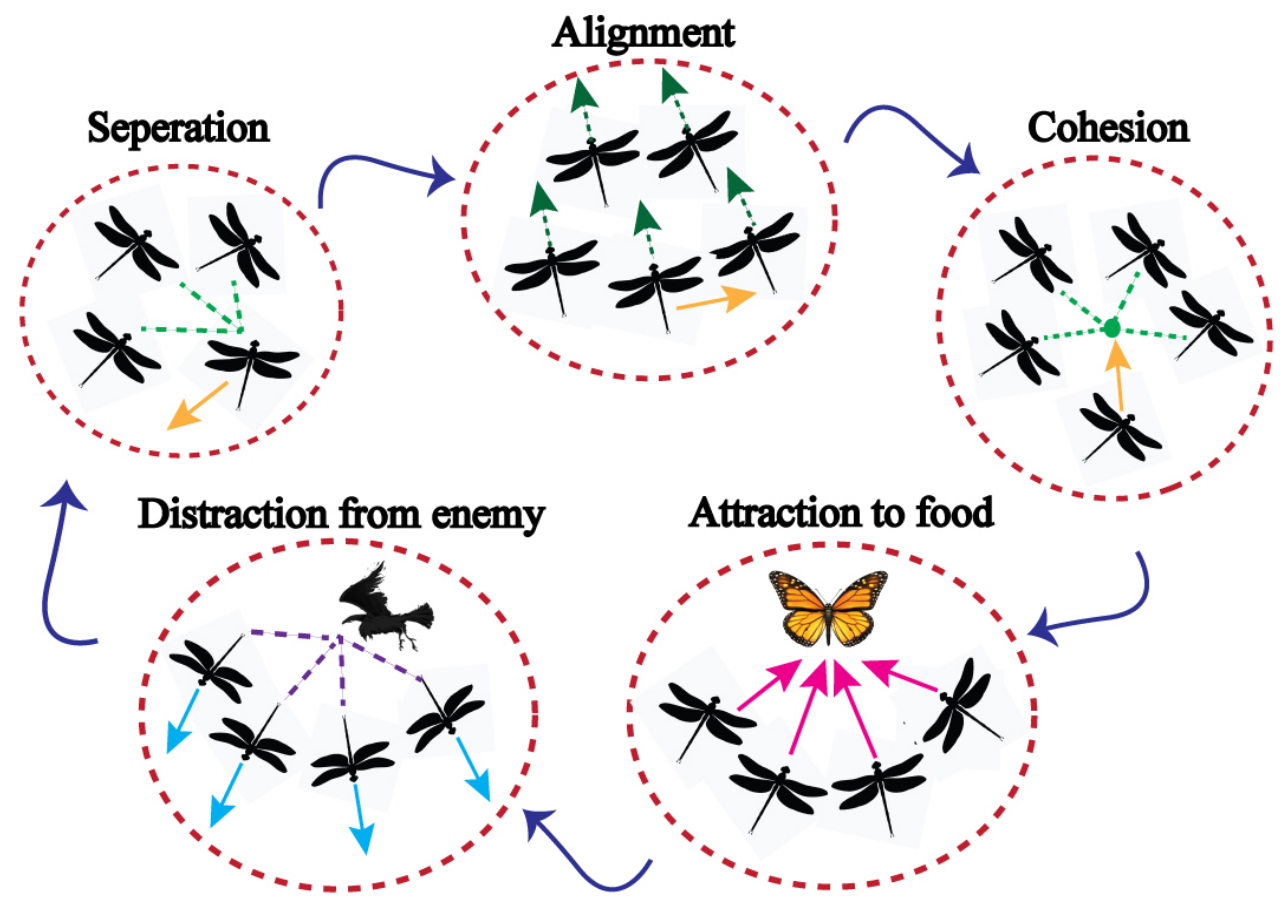

Figure 5. The primitive pattern of DFO Algorithm.

DF's motion in the swarm can be mathematically represented using the following five behaviors known as separation, alignment, cohesion, food, and enemy [40].

1. Separation. In a static swarm, any DF does not collide with the other fly in the neighborhood. The separation $S_{i}$ of the $i^{\text {th }}$ individuals can be computed as $S_{i}=$ $-\sum_{(k=1)}^{N}\left(P-P_{k}\right)$. The present position of DF is denoted by $P, P_{k}$ represents the $k_{t h}$ neighboring DF and $N$ is the total number of individuals neighboring.

2. Alignment. It indicates that the velocity of the other DF matches with the individuals in the same neighbourhood. Alignment represents with the symbol $A_{i}$ and it is computed as $A_{i}=\frac{\sum_{(k=1)}^{N} V_{k}}{N} . V_{k}$ stands for velocity of the $k_{t h}$ neighbouring individuals.

3. Cohesion. It is the liability of individuals to move about the midpoint of the mass of neighborhoods. Cohesion represents as $C_{i}$ and its Equation is as $C_{i}=\frac{\sum_{(k=1)}^{N} P_{k}}{N}-P . P$ denote the current position of the DF's individuals and $P_{k}$ describe the $k_{t h}$ position of neighboring DF.

4. Food. For the sake of survival, all the individuals move towards food. Attraction of food $F_{i}$ at position $x$ is shown $F_{i}=P_{\text {Food }}+P$. The position of current food is represented by $P_{\text {Food }} \& P$ stands for the current individual's position.

5. Enemy. All the individual moves away from the enemy and their equation is given as $E_{i}=P_{\text {Enemy }}+P . P_{\text {Enemy }}$ shows the position of the current enemy and P presents the current individuals position. These five attributes affect the position of individuals DF's. Final upgraded position of the individuals DF's is calculated as $P_{i}=P_{i}+\Delta P_{i}$. Where the value of $\Delta P_{i}$ is given in (16) below as follow:

$$
\Delta P_{i}=W \Delta P_{i}+\left(s S_{i}+a A i+c C_{i}+f F_{i}+e E_{i}\right)
$$

where $s$ describes the weight of separation, $S_{i}$ shows the separation of $i_{t h} \mathrm{DF}, a$ represents the weight of alignment, $A_{i}$ stands for $i_{t h}$ alignment of DF, $c$ denotes the cohesion's weight, $C_{i}$ elaborates the $i_{t h}$ cohesion of DF, $f$ shows the weighting factor 
of food, $F_{i}$ describe the $i t h$ food of $\mathrm{DF}, e$ is the weighting factor of enemy and $E_{t h}$ is the $i_{\text {th }}$ enemy of DF.

\section{Proposed Hybrid (InC-DFO) Technique for PV Energy Systems}

For the sake of making a new strong technique, the authors of this paper merge the powerful characteristics of InC with variable step size and DFO algorithm known as (InC-DFO) technique based on their features in a meta-heuristic context.

The proposed InC-DFO technique is a computational technique that has the advantages of both algorithms. These two techniques are sequentially executed to enhance the effectiveness of the optimization problem. The output of the InC technique with variable step size calculates the initialization of the DFO technique. However, the InC-DFO technique is applied for all weather conditions like UI, partial, and complex partial conditions for PV energy systems. InC-DFO algorithm is used in two stages, in the first stage, the InC technique with variable step size is used because it performs efficiently under UI values and their less convergence and settling time but this technique is trapped on LM and results in power loss.

However, practically it is not possible to achieve constant MPP so there is still some oscillation present around MPP. Thus, a satisfying compromise has to be made among the oscillations and the dynamics for MPPT with fixed step size in the conventional InC technique. The smaller step size can decrease the oscillations around the MPP with decelerating dynamics. On the other side, a larger step size gives the speedy tracking of MPP but it may results in steady-state unavoidable oscillations. For solving these challenges, the InC algorithm is used with variable step size is given as follows:

$$
d k=d(k-1) \pm N *\left|\frac{d e v \times P}{d e v \times V-\operatorname{dev} \times I}\right|
$$

where $d(k-1)$ and $d k$ are the boost converter duty cycle at previous instant $(k-1)$ and at instant $k$. $\mathrm{N}$ represents the scaling factor to adjust the step size. Whereas $d e v \times P, \operatorname{dev} \times V$ and $d e v \times I$ are the output power, voltage and current of PV array respectively. It can be written as follow:

$$
\begin{aligned}
\operatorname{dev} P(k) & =P(k)-P(k-1) \\
\operatorname{dev} V(k) & =V(k)-V(k-1) \\
\operatorname{dev} I(k) & =I(k)-I(k-1)
\end{aligned}
$$

The location of the DF's in global MPP searching of PV systems is the duty ratio at which dc to dc boost converter runs. It is a one-dimensional issue. The PV array's power output is the goal function to be optimized, and the DA is employed to maximize this power. The following procedures are followed to implement the DF algorithm in the second stage for global MPP tracking.

- $\quad$ Step 1: The DF's are dispersed with a one search space within $d_{\min }$ and $d_{\max }$ that are the search space in contexts of duty cycle. The values of $d_{\min }$ and $d_{\max }$ in this article are selected to be and $2 \% \& 98 \%$, correspondingly. The population's value of the step $P_{i}$ is initialized.

- $\quad$ Step 2: PV power of the DF's at each position (duty ratio) is calculated. The food supply and opponent positions are modified as a result of this.

- Step 3: Modified the 's', 'a', 'c', ' $\mathrm{f}$ ', and 'e' values.

- $\quad$ Step 4: The Equations $S_{i}=-\sum_{(k=1)}^{N}\left(P-P_{k}\right)$ and $E_{i}=P_{\text {Enemy }}+P$ are used to compute ' $\mathrm{S}$ ', 'A', ' $C$ ', ' $\mathrm{F}^{\prime}$, and ' $\mathrm{E}$ ' for each individual.

- $\quad$ Step 5: The radius of the neighborhood has been modified.

- $\quad$ Step 6: The DF's positions are changed with the help of equation $P_{i}=P_{i}+\Delta P_{i}$. If this equation produces a location outside of the $d_{\min }$ and $d_{\max }$ bounds, the flies are placed on the other side of the boundary.

- Step 7: Exit the algorithm if the termination criteria are satisfied. 
- $\quad$ Step 8: If the perceived power changes, relaunch the tracking.

Any individual's neighborhood radius is expanded in this application, and the weights ' $\mathrm{f}$ ', ' $\mathrm{c}$ ', ' $\mathrm{a}$ ', 's', and ' $\mathrm{e}$ ' are lowered in accordance with the iteration calculation. This helps the swarm accomplish effective exploration in its early generations. The DF's are more impacted by each other in subsequent rounds as the algorithm approaches convergence. It would also ensure precise convergence and keep the DF's out of local maxima. The opponent and food sources are picked as their best and the worst solutions identified by the swarm up to that point. It enables the swarm to travel towards the best place it has identified thus far while avoiding less promising parts of the search field. The termination criteria for this task is set to be the circumstance in which the mean deviation of all DF's around the optimal location would be less than 5\%. This number can be chosen by the user based on the necessary convergence precision. The pseudocode of DF algorithm [40] is shown in Algorithm 1.

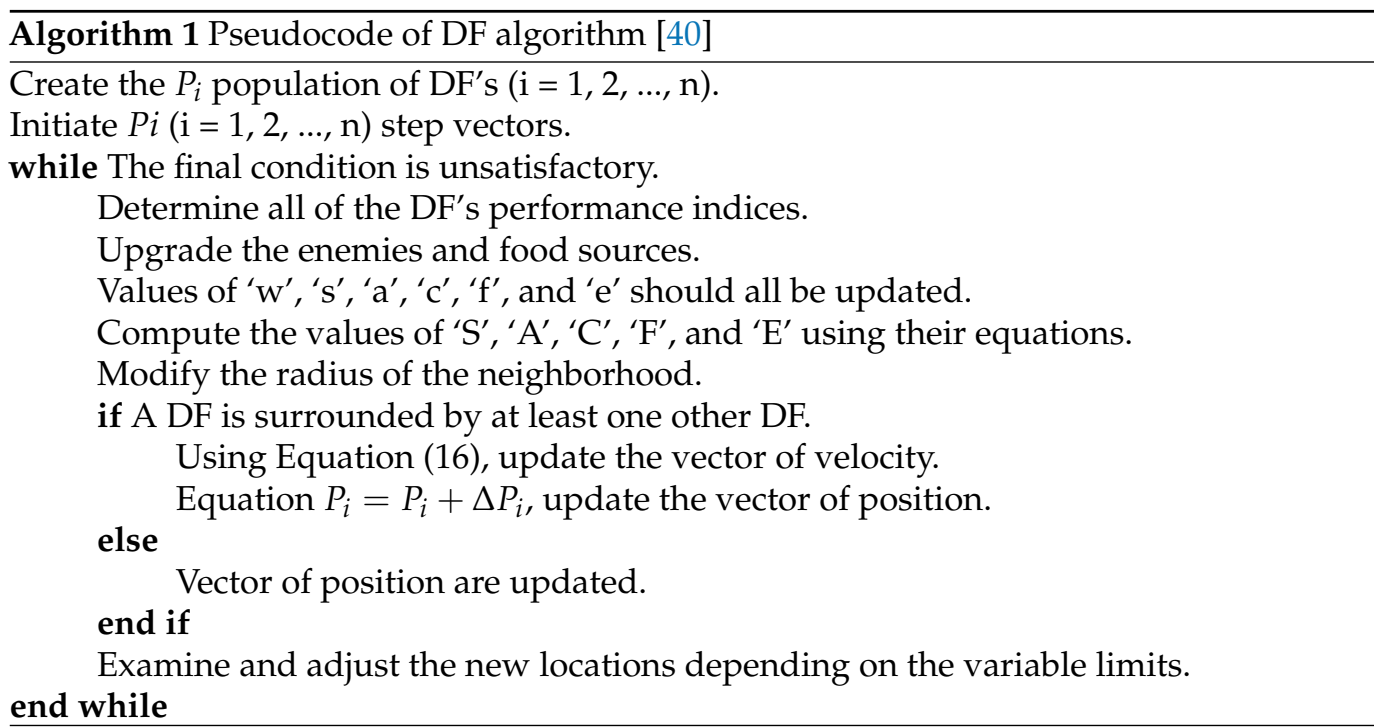

There are many factors in the suggested DF method used for hybridization that has to be fine-tuned. Various exploitative and exploitative behaviors may be created during optimization using separation ' $\mathrm{s}$ ', alignment ' $\mathrm{a}$ ', cohesion ' $c$ ', food ' $\mathrm{f}$ ', and enemy ' $\mathrm{e}$ ' parameters. From these parameters, some of them have constant values and others have changing values according to the scenarios. DF neighbors are extremely essential, therefore each imitation DF is considered to have a neighborhood with a specific radius. In a dynamic swarm, DF tends to coordinate their flight while maintaining adequate separation and coherence. Therefore, in a static swarming, alignments are usually extremely low but cohesiveness is quite strong to assault prey.

As a result, while searching the search space, we give DF low cohesion and high alignment weights, whereas when exploiting the search space, we give DF's high cohesion and low alignment. The radius of neighborhoods is enhanced linearly with the number of iterations when transitioning from exploration to exploitation. The food supply and opponent are picked from among the best and worst solutions discovered thus far by the entire swarm. This results in convergence into promising portions of its optimal solution and divergence away from non-promising ones. Various exploratory or exploiting swarm behaviors can also be obtained with varying weight levels. For exploiting, the value of ' $\mathrm{c}$ ' is kept large, but an is kept low because static swarming requires strong cohesion and low orientation. In a dynamic swarm, but on the other hand, ' $c$ ' is maintained modest while an is raised for better exploration qualities.

A heuristic method in MPP tracking aims to identify GM in its transient state with the least amount of time and reduce oscillations in the steady-state surrounding GM to decrease power loss. DF algorithm is used to improve MPP searching by considering these 
two features. In our approach, the duty cycle represents the search space, which accepts values between 0 and 1 . The output duty cycle and the location of the DF are related. Within the search space, the solution is generated at random. Except for initiation, the method stages are repeated until the stopping condition is fulfilled or the maximum number of iterations is reached. The greatest value of PV power at GM is the fitness function.

\section{Partial Shading Detection Method to Transfer from InC to DFO}

To comprehend the PS detection mechanism of the InC-DFO technique, it is important to figure out the I-V curve relationship of a single diode PV cell. The complete P-V curves of the PV system are shown in Figure 6 that consist of UI, PS1, and PS2 conditions.

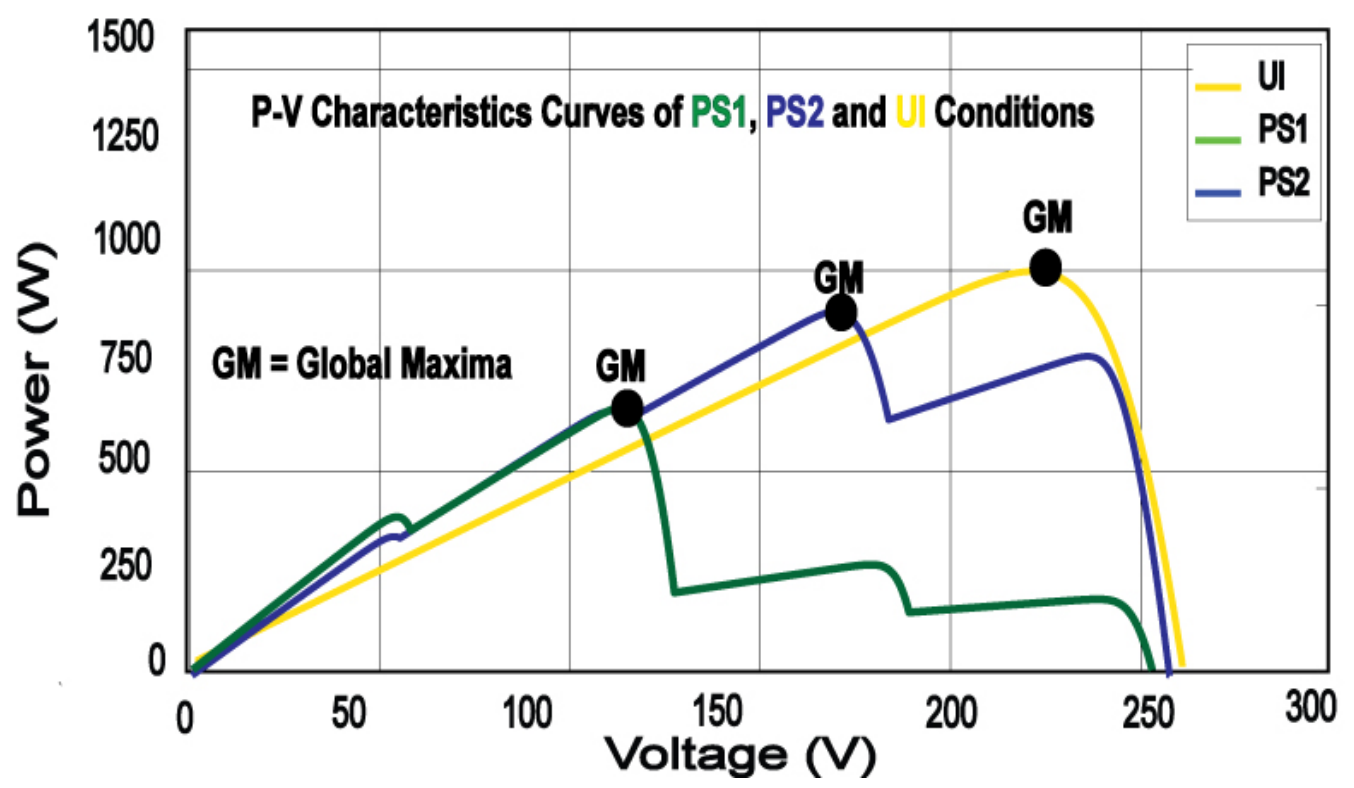

Figure 6. Complete P-V curves of PV system.

For this aim, an equivalent circuit model is examined. We calculate the value of $I_{p v}$ from (5).

$$
I_{p v}=\frac{G}{G_{S T C}}\left(I_{p v, S T C}+K \Delta T\right)
$$

where ' $K$ ' stands for Boltzmann constant, ' $T$ ' is expressed as the temperature of the photovoltaic cell and $G$ represents the irradiance. If the value of $T$ is remaining constant and $G$ is assumed to be varying then $I_{p v}$ rewritten as follow:

$$
\frac{I_{p v}}{I_{p v, S T C}}=\frac{G}{G_{S T C}}
$$

$I_{p v, S T C}$ is the photovoltaic current at standard testing condition i.e., $1000 \mathrm{~W} / \mathrm{m}^{2}$ at $25^{\circ} \mathrm{C}$. From [41], taking into consideration that maximum current $I_{m p p}$ exists in the vicinity of $0.9 I_{S C}$, Equation (22) can be written as

$$
\begin{gathered}
\frac{I_{S C}}{I_{S C, S T C}} \approx \frac{I_{m p p}}{I_{m p p, S T C}} \approx \frac{G}{G_{S T C}} \\
G \approx \frac{I_{m p p}}{I_{m p p, S T C}} G_{S T C} \approx \frac{I_{S C}}{I_{S C, S T C}} G_{S T C}
\end{gathered}
$$

The detection strategy of InC-DFO takes $I_{m p p}$ and $I_{s c}$ points on I-V curves of the Sun Power SPR-315E-WHT-D module and their specifications are given in Table 1. The irradiance values that are chosen from the I-V curve are demonstrated in Figure 7. 
Table 1. Electric characteristics of Sun Power SPR-315E-WHT-D.

\begin{tabular}{ll}
\hline \multicolumn{1}{c}{ Description } & $\begin{array}{l}\text { Electric Characteristics of Sun Power } \\
\text { SPR-315E-WHT-D }\end{array}$ \\
\hline Maximum Power $\left(P_{\max }\right)$ & $315.072 \mathrm{~W}$ \\
\hline Voltage at MPP $\left(V_{\max }\right)$ & $54.7 \mathrm{~V}$ \\
\hline Current at MPP $\left(I_{\max }\right)$ & $5.76 \mathrm{~A}$ \\
\hline Short circuit current $\left(I_{s c}\right)$ & $6.14 \mathrm{~A}$ \\
\hline Open circuit voltage $\left(V_{o c}\right)$ & $64.6 \mathrm{~V}$ \\
\hline Temperature coefficient of $\left(V_{o c}\right)$ & $-0.176 .6 \mathrm{mV} / \mathrm{K}$ \\
\hline Temperature coefficient of $\left(I_{s c}\right)$ & $3.5 \mathrm{~mA} / \mathrm{K}$ \\
\hline Temperature coefficient of power & $-0.38 \% / \mathrm{K}$ \\
\hline Peak efficiency & $19.3 \%$ \\
\hline
\end{tabular}

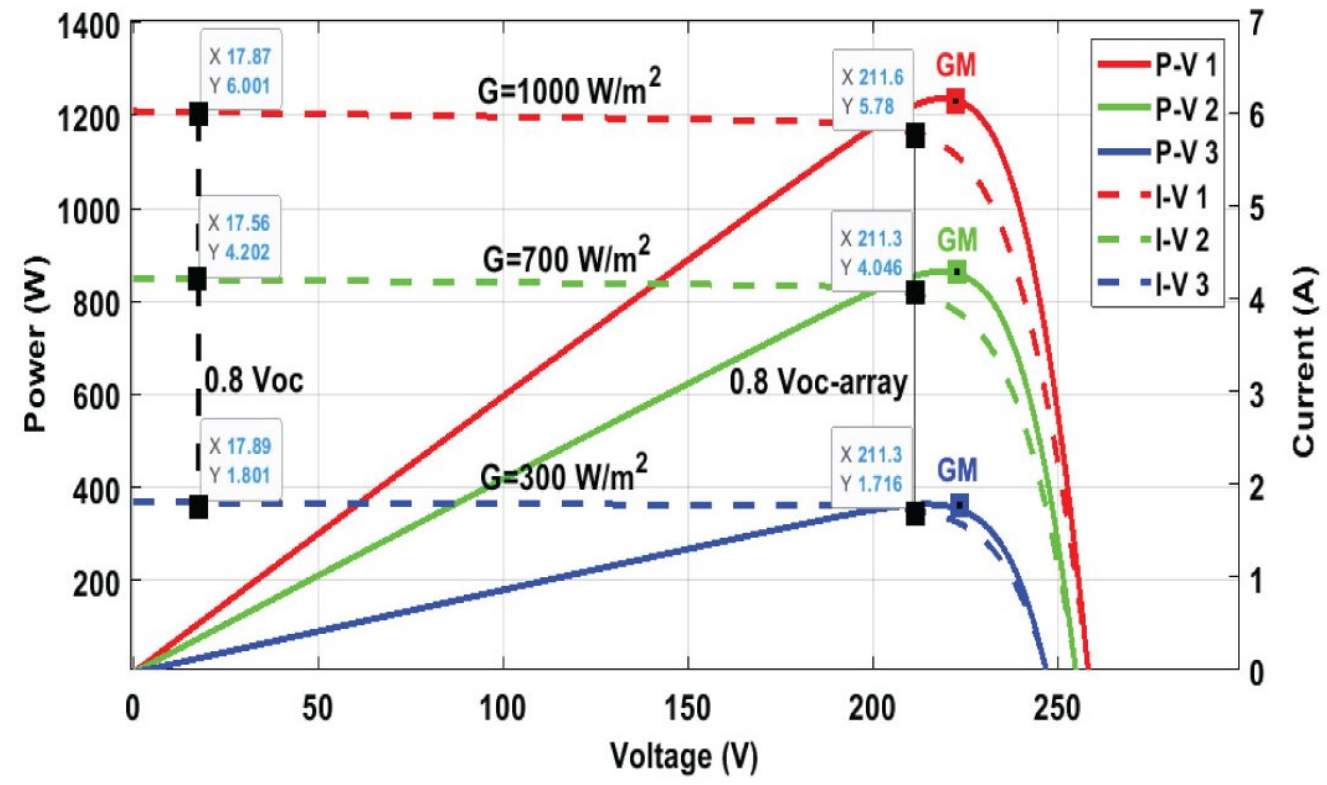

Figure 7. I-V and P-V curves of the PV system.

When values of $\mathrm{G}$ drops from $1000 \mathrm{~W} / \mathrm{m}^{2}$ to $700 \mathrm{~W} / \mathrm{m}^{2}$, it is noticed that the ratio of $I_{s c}$ results as

$$
\frac{I_{S C}}{I_{s c, S T C}}=\frac{4.202}{6.14}=0.684 \approx 0.7
$$

Respectively, the same outcomes could be drawn during the change in MPP current ratio when $G$ falls from $1000 \mathrm{~W} / \mathrm{m}^{2}$ to $700 \mathrm{~W} / \mathrm{m}^{2}$, i.e.,

$$
\frac{I_{m p p}}{I_{m p p, S T C}}=\frac{4.046}{5.867}=0.689 \approx 0.7
$$

It is observed from the (24), that the measured values of irradiance at $I_{m p p}$ and $I_{s c}$ are approximately equal. In [41], $I_{m p p}$ conceals near the 0.8 open-circuit voltage of a selected array $V_{o c-a r r a y}$ and $I_{s c}$ is in the region of 0.8 open-circuit voltage $V_{o c}$ of a module. Consequently, $I_{m p p}$ and $I_{s c}$ may be denoted as $I_{0.8 V o c-a r r a y}$ and $I_{0.8 V o c}$, respectively. So, (24) could be written using these terms:

$$
G \approx \frac{I_{0.8 V o c-a r r a y}}{I_{m p p, S T C}} G_{S T C} \approx \frac{I_{0.8 V o c}}{I_{S c, S T C}} G_{S T C}
$$


MPPT records the corresponding currents as $0.8 \mathrm{Voc}$ - array and $0.8 \mathrm{Voc}$ when they take a sample at $0.8 \mathrm{Voc}$ - array and $0.8 \mathrm{Voc}$ respectively. Values of $\mathrm{G}$ are determined at $0.8 V o c$ - array and $0.8 V o c$ is specified as G-1 and G-2, respectively.

In UI condition, values of G-1 and G-2 are almost identical due to the slope current between $I_{0.8 \mathrm{Voc}}$, and $I_{0.8 \mathrm{Voc}-\text { array }}$ is very small. This phenomenon is clarified in Figure 7 through the $\mathrm{I}-\mathrm{V}$ characteristics curve. At 3 different values of $\mathrm{G}$ i.e., $1000 \mathrm{~W} / \mathrm{m}^{2}, 700 \mathrm{~W} / \mathrm{m}^{2}$ and $300 \mathrm{~W} / \mathrm{m}^{2}$ of PV array, corresponding currents are labeled at $I_{0.8 \mathrm{Voc}}$, and $I_{0.8 \mathrm{Voc}-\text { array }}$. So, the values of G-1 and G-2 are calculated using (27) at $I_{0.8 \mathrm{Voc}}$ and $I_{0.8 \mathrm{Voc} \text {-array sequentially }}$ as follows:

$$
\begin{aligned}
G-1 & =\frac{I_{0.8 V o c}}{I_{S c, S T C}} G_{S T C} \\
& =\frac{6.001}{6.14} \times 1000=977 \\
G-2 & =\frac{I_{0.8 V o c-a r r a y}}{I_{m p p, S T C}} G_{S T C} \\
& =\frac{5.78}{5.76} \times 1000=1003
\end{aligned}
$$

It is concluded from (28) and (29) that G-1 and G-2 values are near to the real value of G like $1000 \mathrm{~W} / \mathrm{m}^{2}$. Though, (27) is estimated on the basis such that $I_{m p p}$ is situated at $0.9 I_{s c}$. This consideration is not mandatory correct for all values of $\mathrm{G}$ because of creating a mismatch value. In above discussed computation, mismatch value is $23 \mathrm{~W} / \mathrm{m}^{2}$ among G-1 and G-2 at $1000 \mathrm{~W} / \mathrm{m}^{2}$ at $1000 \mathrm{~W} / \mathrm{m}^{2}$. However, $\mathrm{G}$ mismatch value at $700 \mathrm{~W} / \mathrm{m}^{2}$ between G-1 and G-2 is reduced to $12 \mathrm{~W} / \mathrm{m}^{2}$, whereas at $300 \mathrm{~W} / \mathrm{m}^{2} \mathrm{G}$ mismatch value within G-1 and $\mathrm{G}-2$ is decreased closely to zero.

Based on the mismatch values of $G$, an important conclusion could be constructed that in stage one, InC techniques with variable step size, act as UI conditions for a below specific threshold value of irradiance. This threshold value 40 is calculated by authors [42] on I-V curves using an extensive survey of ten poly and mono-crystalline different PV modules. Therefore, it could be deduced that if the value of mismatch is greater than $40 \mathrm{~W} / \mathrm{m}^{2}$ then the PS condition is prevailing and it acts as a UI condition for less than $40 \mathrm{~W} / \mathrm{m}^{2}$.

$$
\begin{array}{ll}
|G 1-G 2|>40 P S & \text { Condition } \\
|G 1-G 2|<40 U I & \text { Condition }
\end{array}
$$

To overcome the problem of power loss, the bio-inspired DFO technique is used in the second stage for searching the GM. InC technique with variable step size initiate in stage one and force the PV energy system to converge to 80 percent of $I_{s c}$. once the InC algorithm achieved the $I_{S C}$ then it triggers the DFO algorithm which settles the PV array to exact MPP. Thus, InC-DFO not only removes the cons of both methods but also searches the MPP at PS and CPS conditions. The flowchart of the proposed InC-DFO algorithm is given in Figure 8. 


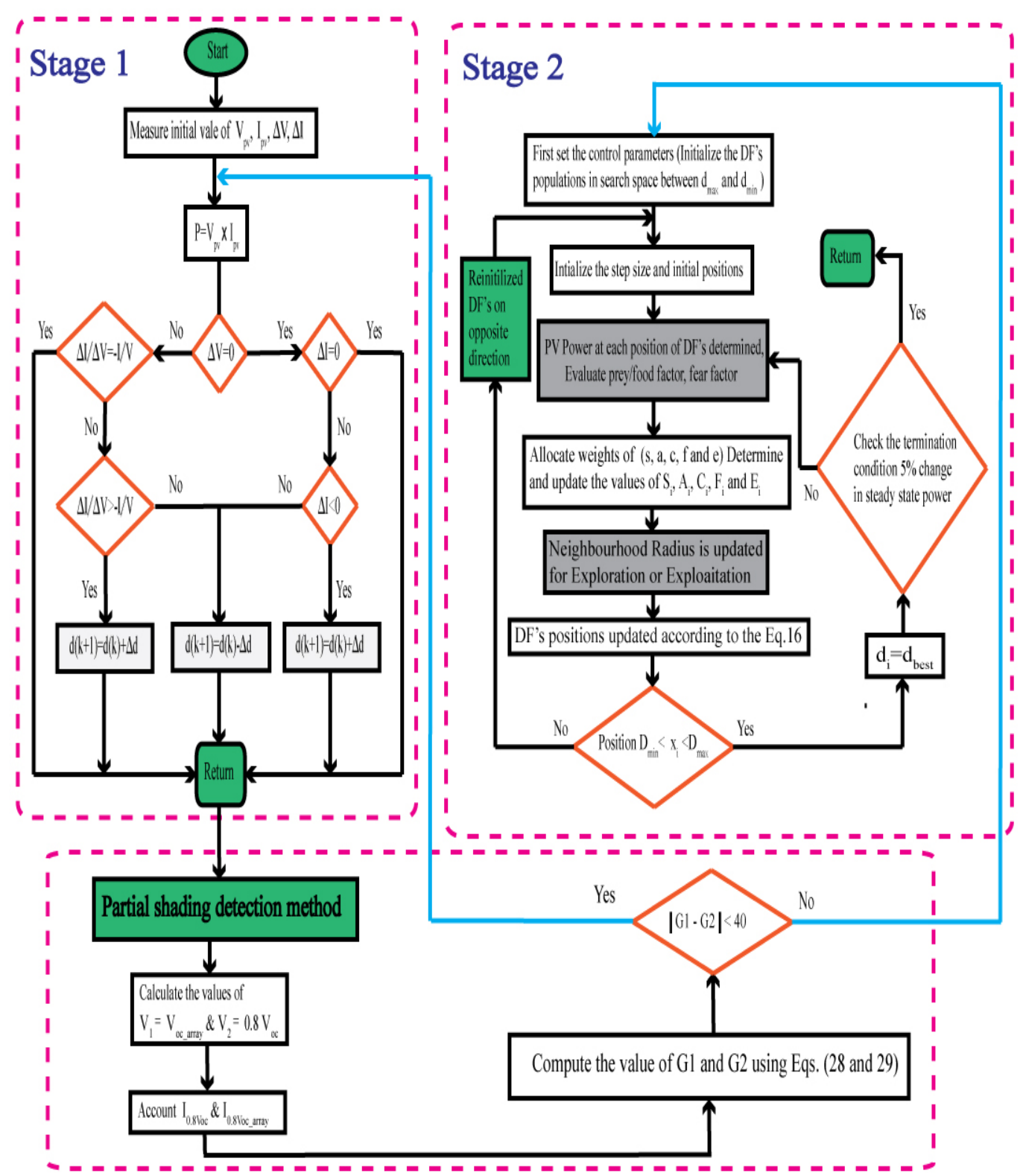

Figure 8. Flowchart of Proposed Hybrid (InC-DFO) Technique.

\section{Simulation Model}

Figure 9 illustrates the MPPT methods' implementation in a commonly used PV system design. The PV model presented by [43] is used to build the entire arrangement. Four modules are linked in series to form a PV array. $P_{m p p}=200 \mathrm{~W}, V_{m p p}=26 \mathrm{~V}, V_{o c}=32.9 \mathrm{~V}$, $I_{m p}=7.6 \mathrm{~A}, I_{s c}=8.21$ are the parameters for the PV module. The implementation of the developed Hybrid(InC-DFO) based MPPT is assessed using a PV array that is exposed to a variety of partial shade patterns. The PV array and the battery load are connected via a boost converter. The parameters of the DC to DC converter are $C_{\text {in }}=10 \mathrm{uF}, \mathrm{L}=200 \mathrm{uH}$, $C_{o u t}=47 \mathrm{uF}$, and $F_{s w}=20 \mathrm{kHz}$, as computed in [44]. As illustrated in Figure 9, the MPPT methods have been performed in embedded blocks. This block accepts $I_{p v}$ and $V_{p v}$ as inputs and outputs the duty cycle of a DC to DC boost converter. 


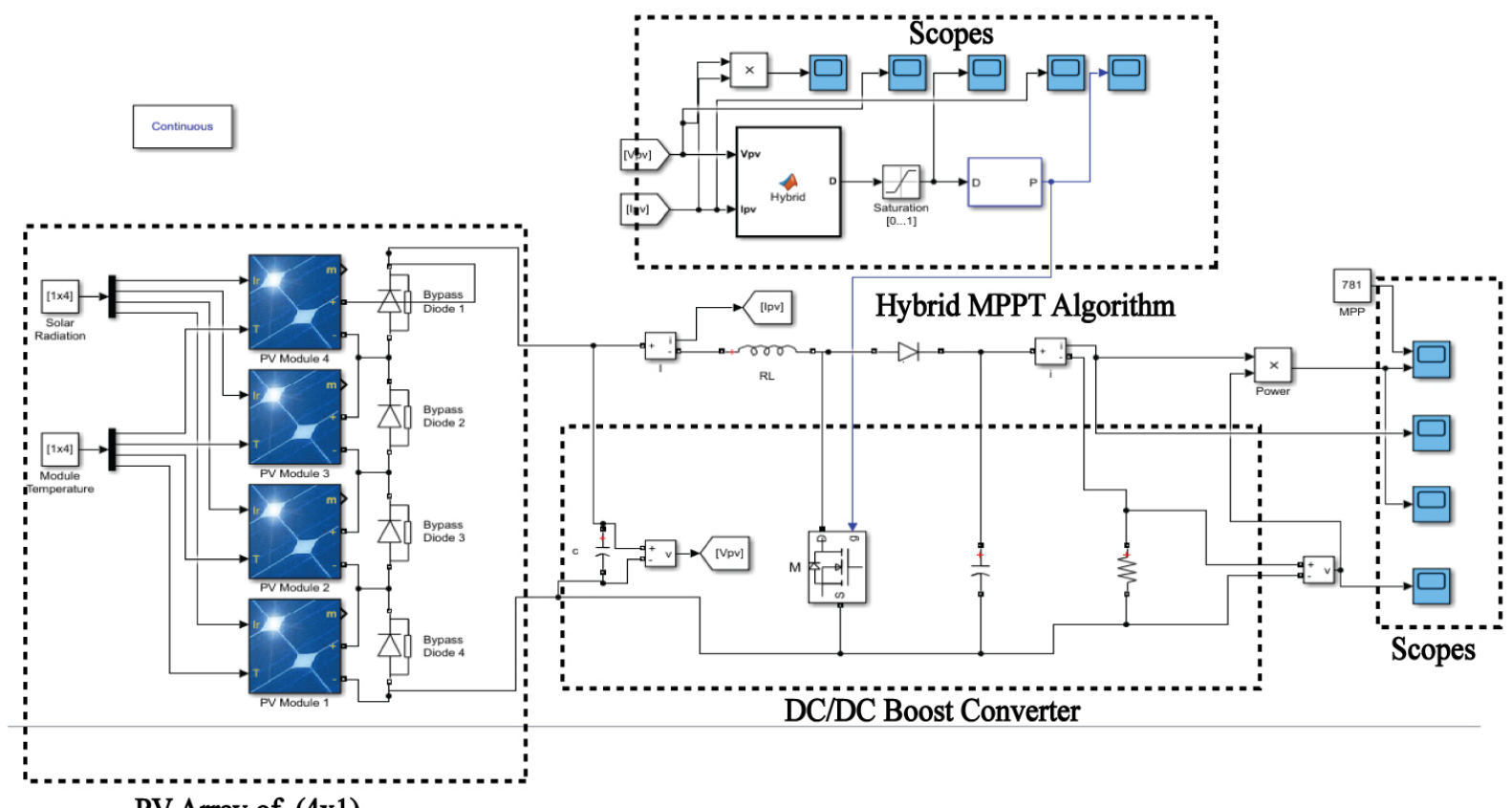

PV Array of $(4 \times 1)$

Figure 9. Simulation Model.

\section{Results and Discussion}

Four cases are described in this section for all-weather conditions e.g., UI, PS, and CPS conditions. From four cases, one is taken for UI, two for PS, and one for CPS. After different results and trails, 4 distant cases in terms of different irradiance values are chosen for performance calculation of nature-inspired algorithms. A model of PV energy system has been developed on the MATLAB/Simulink software. In a PV energy system model, the rating of a single PV module is given in Table 1.

All previous algorithms like InC, CS, PSO, DFO, FA, and ACO, and the proposed MPPT Hybrid (InC-DFO) technique are tested on the developed PV model. Four cases are used for testing all MPPT techniques for PV energy systems in which UI condition is illustrated in case 1. PS condition is described in cases 2 and 3. CPS condition expresses in case 4 . On the basis of settling and tracking time, current, transients of voltage, power, efficiency, and oscillation, results are analyzed. All four cases and their results are discussed as follows.

\subsection{Case 1. Uniform Irradiance Condition}

All the modules of the PV system received the same irradiance level in this case and it changes with respect to time. The irradiance pattern is described in Table 2. Figure 7 presents the PV energy systems UI curves of P-V and I-V. The pattern of uniform irradiance that is taken is elaborated in Table 2.

When comparing the power of different techniques, it is observed that the power at GM is $864 \mathrm{~W}$ and the highest power tracked at $700\left(\frac{\mathrm{KW}}{\mathrm{m}^{2}}\right)$ irradiance level is $863.4 \mathrm{~W}$ in case of uniform irradiance condition for proposed hybrid (InC-DFO) technique. While comparing the power of all techniques, FA has the lowest power $852 \mathrm{~W}$. The tracked power in the sequence is as follows: Hybrid $>D F O>I n C>C S>A C O>P S O>F A$. CS algorithm has more oscillation and the highest setting time of $1.94 \mathrm{~s}$. Among all the techniques, FA tracked the least power of $852 \mathrm{~W}$. The proposed hybrid technique saves power loss by reducing the oscillation and enhancing the efficiency of $99.93 \%$ of PV energy systems. CS has the highest oscillations that cause power loss when compared to other techniques. 
Table 2. P-V and I-V characteristic curves at different irradiance values.

\begin{tabular}{|c|c|c|c|c|}
\hline Case & & rradiance $S_{i}$ & & Power $_{\text {max }}$ \\
\hline Case 1 UI & $\begin{array}{l}\text { PV-1:0.70 } \\
\text { PV-4:0.70 }\end{array}$ & PV-2:0.70 & PV-3:0.70 & $864 \mathrm{~W}$ \\
\hline Case 2 PS1 & $\begin{array}{l}\text { PV-1:1.00 } \\
\text { PV-4:0.20 }\end{array}$ & PV-2:0.80 & PV-3:0.10 & $512 \mathrm{~W}$ \\
\hline Case 3 PS2 & $\begin{array}{l}\text { PV-1:0.90 } \\
\text { PV-4:0.50 }\end{array}$ & PV-2:1.00 & PV-3:0.80 & $781 \mathrm{~W}$ \\
\hline Case 4 CPS & $\begin{array}{l}\text { PV-1:1.10 } \\
\text { PV-4:0.40 } \\
\text { PV-7:0.90 } \\
\text { PV-10:0.20 }\end{array}$ & $\begin{array}{l}\text { PV-2:0.25 } \\
\text { PV-5:1.00 } \\
\text { PV-8:0.40 }\end{array}$ & $\begin{array}{l}\text { PV-3:0.84 } \\
\text { PV-6:0.50 } \\
\text { PV-9:0.80 }\end{array}$ & $1250 \mathrm{~W}$ \\
\hline
\end{tabular}

To reduce the oscillation, the value of step size could be reduced that can cause increases in tracking time. The range of step size of the DC to DC boost converter should be between 2 to 5 percent of PV arrays power to balance the efficiency and tracking time. In CS, levy flight causes large fluctuations. It is determined that among all the techniques, the hybrid technique has the largest efficiency, no oscillations, fast-tracking time, least convergence time of $0.50 \mathrm{~s}$, and settling time of $0.59 \mathrm{~s}$.

\subsection{Case 2. Partial Shading Condition}

In case 2 partial shading is discussed and their irradiance pattern is presented in Table 2. Partial shading occurs because of not receiving equal irradiance values by PV arrays. Bypass diodes are used for less-performing diodes due to PS. There are multiple peaks that appear on the I-V and the P-V characteristics curve that can result in complications for searching the peaks. Furthermore, multiple peaks are characterized as a number of LM and single GM. Conventional techniques cannot differentiate between LM and GM that may result in the reduction of power loss. The I-V and P-V characteristic curves of PS cases 2 and 3 are described in Figure 10. There are three LM and single GM observed on the I-V and P-V characteristics curve. The value of GM for PS1 is $512 \mathrm{~W}$.

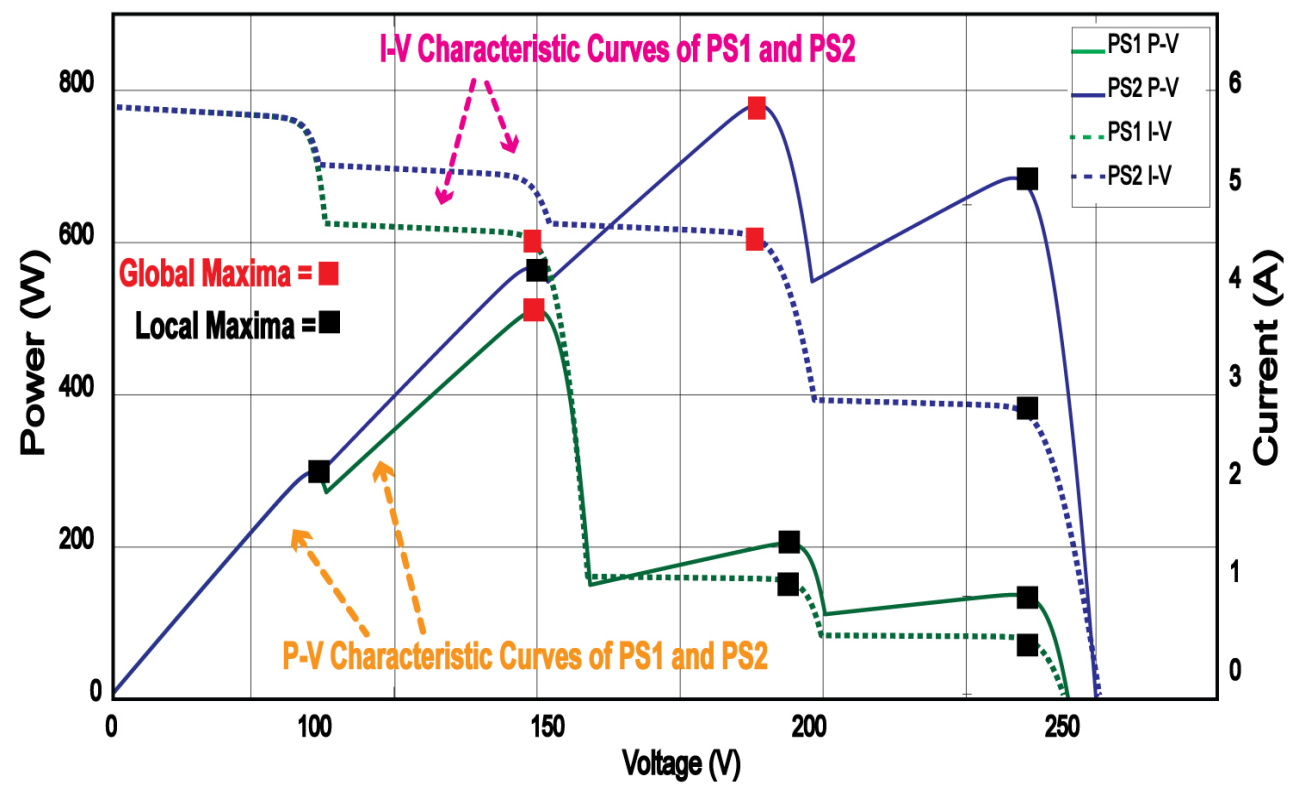

Figure 10. P-V and I-V Characteristics Curves for Partial Shading Cases 2 and 3. 
The proposed InC-DFO technique successfully obtained the GM value for the PS condition. Power tracked by proposed hybrid and all other DFO, CS, PSO, FA, InC, and ACO techniques are $511.4 \mathrm{~W}, 509 \mathrm{~W}, 506 \mathrm{~W} .498 \mathrm{~W}, 325 \mathrm{~W}$, and $507 \mathrm{~W}$, respectively. ACO techniques are stuck on LM1 and cannot find GM. PSO techniques have the highest oscillations and settling time of $1.80 \mathrm{~s}$ which results in loss of power and therefore their efficiency also decreases. Conventional InC techniques tracked the lowest power. The settling time of PSO, DFO, InC, Hybrid, CS, FA, and ACO techniques are 1.80 s, 0.75 s, 0.52 s, 0.62 s, 1.78 s, $1.30 \mathrm{~s}$, and $0.93 \mathrm{~s}$, respectively. Power, Current and Voltage comparison of all techniques for Case 1 and Case 2 are shown in Figure 11.

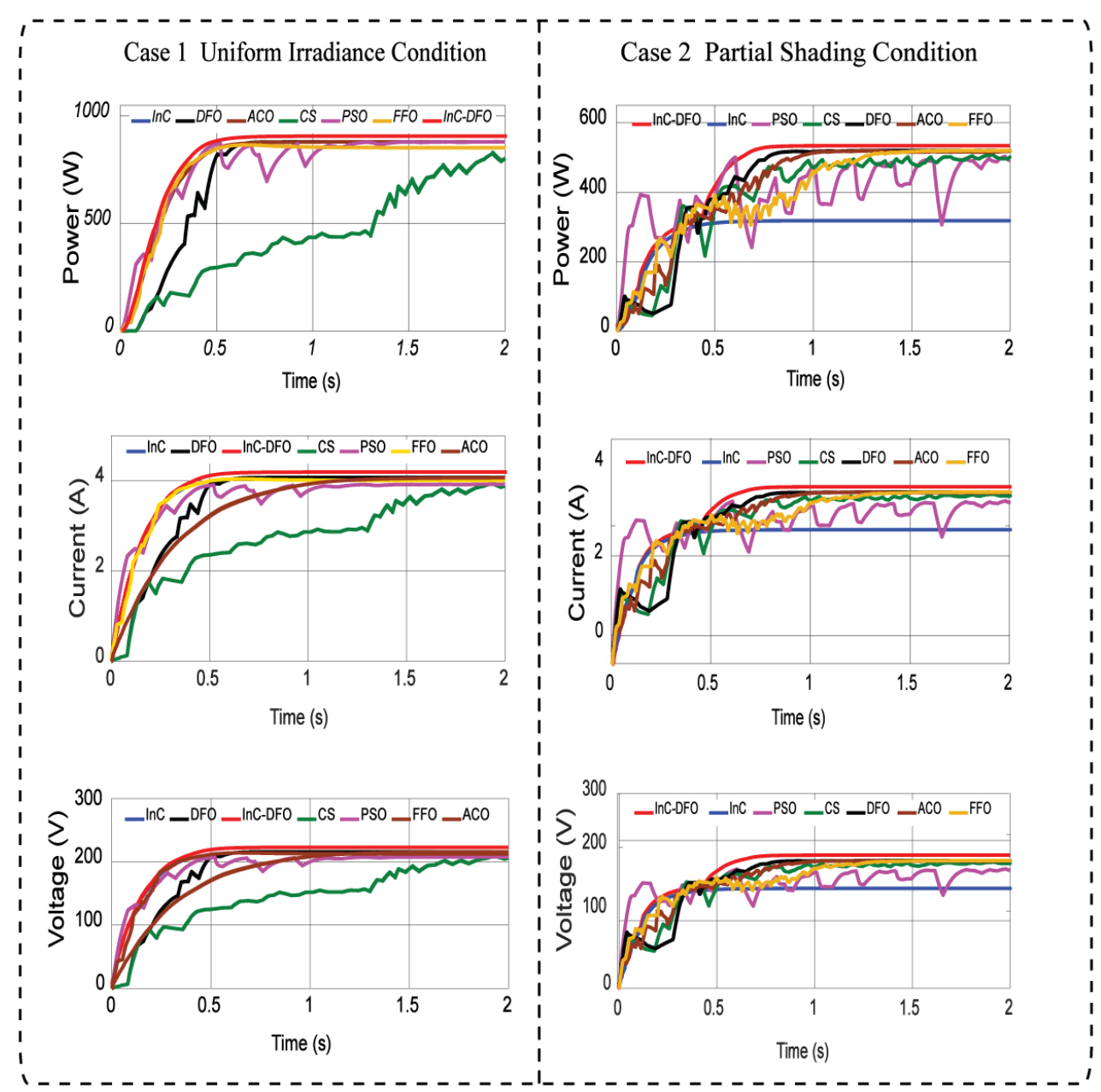

Figure 11. Power, Current and Voltage comparison of all techniques for Case 1 and Case 2.

\subsection{Case 3. Partial Shading Condition}

Case three also represents another PS condition and their irradiance pattern is illustrated in Table 2. The value of GM is tracked in this case of PS. The Value of GM tracked is $781 \mathrm{~W}$. In case 2 of partial shading, a $4 \times 1 \mathrm{PV}$ array is used. The power of the proposed hybrid technique is compared with other DFO, PSO, CS, FA ACO, and InC techniques. Among all the techniques PSO has the highest oscillation and ACO has no oscillation but they cannot find the GM and are stuck on LM. Power loss occurs due to oscillation in the PV system.

The Power of DFO, PSO, CS, FA, InC, ACO, and hybrid techniques are $780 \mathrm{~W}, 779 \mathrm{~W}$, $770.2 \mathrm{~W}, 769 \mathrm{~W}, 712 \mathrm{~W}, 768 \mathrm{~W}$, and $780.4 \mathrm{~W}$, respectively. InC algorithm shows the lowest efficiency of 91.17 among all the techniques and it has the 2nd lowest convergence time of $0.22 \mathrm{~s}$. The drawback of the InC technique is that it is stuck on LM which results in loss of 
power. InC technique with variable step size has the lowest settling and convergence time that's why the proposed hybrid technique uses two stages.

The convergence time of PSO, DFO, InC, InC-DFO, CS, FA and ACO techniques are $1.10 \mathrm{~s}, 0.53 \mathrm{~s}, 0.22 \mathrm{~s}, 0.20 \mathrm{~s}, 1.41 \mathrm{~s}, 1.01 \mathrm{~s}$, and $0.31 \mathrm{~s}$, respectively. When comparing all the techniques it is observed that InC has the least convergence time. The settling time of ACO, FA, CS, hybrid, InC, DFO, and PSO are 0.35 s, 1.42 s, 1.93 s, 0.89 s, 0.22 s, 0.73 s, and 1.65 s, respectively. It is noted that the proposed technique presents the lowest settling time that decreases the power losses and enhances the efficiency of the PV energy systems. CS has the highest settling time that may result in loss of power.

\subsection{Case 4. Complex Partial Shading Condition}

Condition of CPS presents in case 4 and their irradiance pattern is illustrated in Table 2. Figure 12 shows the P-V \& I-V characteristics curve of CPS phenomena.

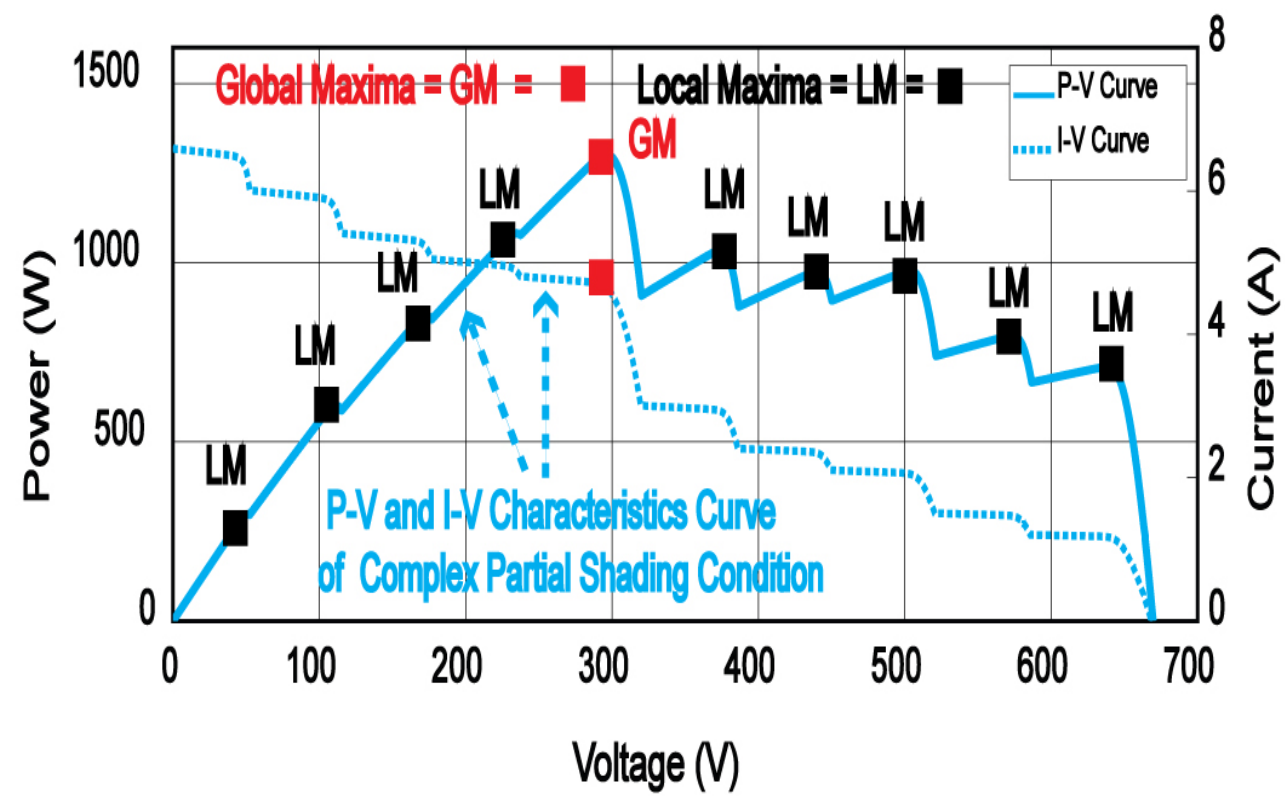

Figure 12. P-V and I-V Characteristics Curves for Complex Partial Shading Cases.

In the CPS case, 10 different ratings of PV modules are taken and they are connected in series. A duty cycle of a DC/DC boost converter is utilized to search the MPPT. The proposed hybrid technique is compared with the other DFO, PSO, CS, FA, ACO, and InC techniques and it is observed that The value of GM in the CPS case is $1250 \mathrm{~W}$.

Power of proposed hybrid and all previous PSO, DFO, InC, hybrid, CS, FA, and ACO techniques are $1246 \mathrm{~W}, 1248 \mathrm{~W}, 1094 \mathrm{~W}, 1249.8 \mathrm{~W}, 1243 \mathrm{~W}, 1157 \mathrm{~W}$, and $1247.1 \mathrm{~W}$, respectively. The hybrid algorithm gives the highest power among all the techniques. InC technique with variable step size cannot find the GM and is stuck on LM but it has the lowest convergence and settling time of $0.39 \mathrm{~s}$ and $0.45 \mathrm{~s}$, respectively. PSO method shows that it has the highest oscillation among all the techniques that cause the reduction of power loss of the PV system. The settling time of ACO, FA, CS, Hybrid, InC, DFO, and PSO techniques are $1.4 \mathrm{~s}, 1.80 \mathrm{~s}$, $1.82 \mathrm{~s}, 0.75 \mathrm{~s}, 0.45 \mathrm{~s}, 0.83 \mathrm{~s}$, and $1.91 \mathrm{~s}$ respectively. It is noted that the proposed InC-DFO method describes the lowest settling time of $0.75 \mathrm{~s}$. PSO gives a higher oscillation that decreases the power of the PV system. The convergence time of PSO, DFO, InC, hybrid, CS, FA, and ACO techniques are $1.31 \mathrm{~s}, 0.69 \mathrm{~s}, 0.39 \mathrm{~s}, 0.41 \mathrm{~s}, 0.73 \mathrm{~s}, 0.52 \mathrm{~s}$, and $0.59 \mathrm{~s}$, respectively.

The proposed method can remove the oscillation of the PSO and CS algorithm, thus increasing the efficiency of the PV energy systems. However, InC gives the lowest efficiency $87.52 \%$ because it is not able to find GM and is stuck on any value of LM.

In the case of CPS, the hybrid algorithm achieved the highest efficiency $99.98 \%$. In the first stage, the InC technique is used because of less settling time but it is stuck in local 
maxima and cannot find the GM. So, in the second stage, we use the DFO that has the highest capability of tracking power. The proposed hybrid technique has zero oscillation and the highest convergence time that results in enhancing the efficiency of the PV system. Power, Current, and Voltage comparison of all techniques for Case 3 and Case 4 are represented in Figure 13.

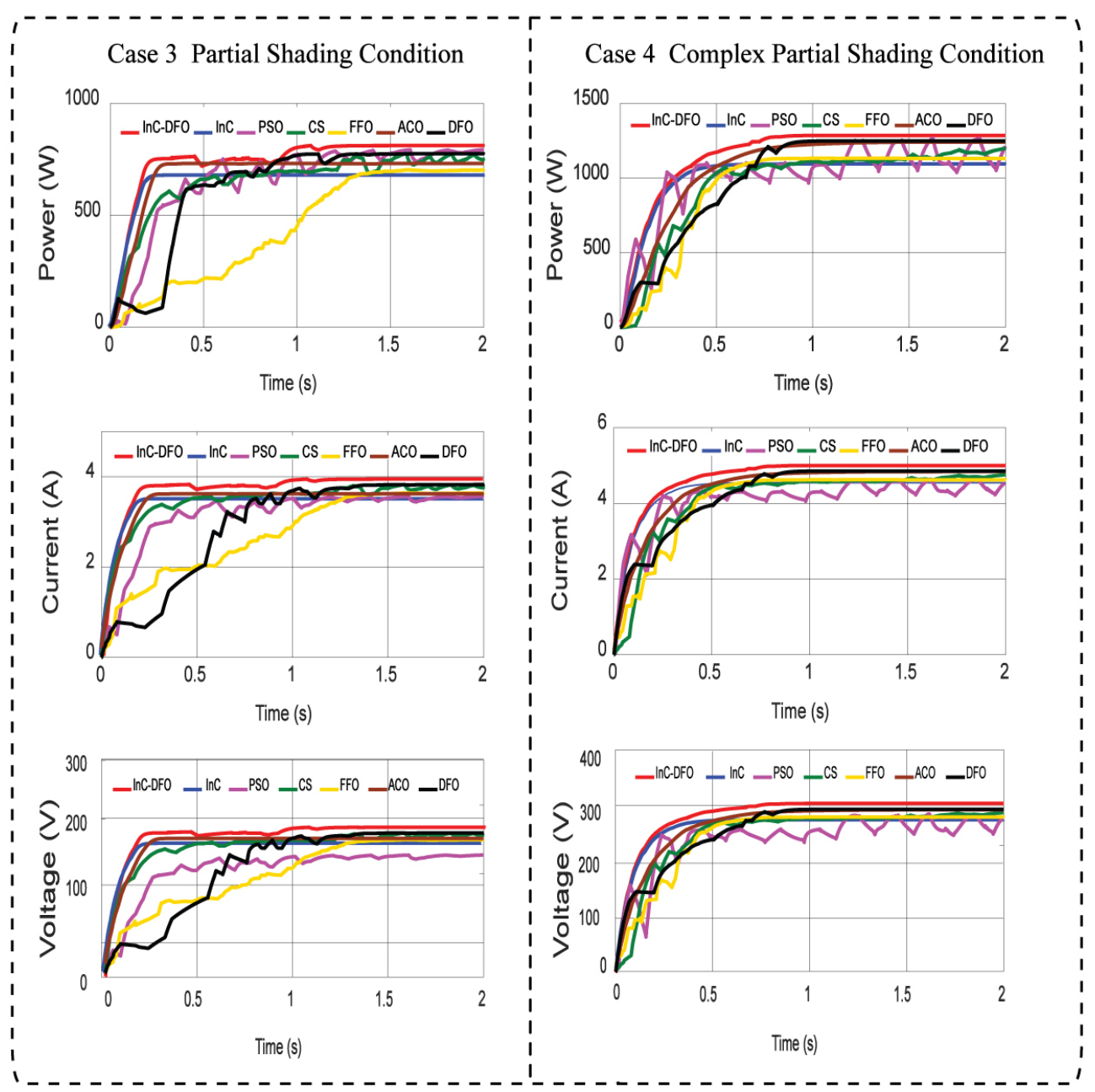

Figure 13. Power, Current, and Voltage comparison between all techniques for Case 3 and Case 4 .

To validate the effectiveness of the proposed (InC-DFO) and its comparison with six other MPPT techniques, four different cases of PV array are taken for all weather conditions. Among four cases, one is for UI condition, two cases for partial shading condition (PSC), and one is for CPS condition. On the basis of these four cases, the performance valuation of the PV system is carried out and their numerical analysis is illustrated in Table 3. 
Table 3. Comparative Analysis between Proposed and Previous MPPT Techniques for all Weather Conditions.

\begin{tabular}{|c|c|c|c|c|c|c|c|}
\hline Case & Technique & $\begin{array}{l}\text { Convergence } \\
\text { Time (s) }\end{array}$ & $\begin{array}{l}\text { Settling } \\
\text { Time (s) }\end{array}$ & $\begin{array}{l}\text { Maximum } \\
\text { Power } \\
\text { (Watt) }\end{array}$ & $\begin{array}{l}\text { Power } \\
\text { Tracked } \\
\text { (Watt) }\end{array}$ & $\begin{array}{l}\text { Efficiency } \\
(\%)\end{array}$ & $\begin{array}{l}\text { GM } \\
\text { De- } \\
\text { tected }\end{array}$ \\
\hline \multirow{7}{*}{ 1.UIC } & PSO & 0.80 & 1.10 & 864 & 862 & 99.77 & Yes \\
\hline & DFO & 0.53 & 0.61 & 864 & 863.3 & 99.92 & Yes \\
\hline & InC & 0.52 & 0.60 & 864 & 863.1 & 99.90 & Yes \\
\hline & Hybrid & 0.50 & 0.59 & 864 & 863.4 & 99.93 & Yes \\
\hline & CS & 1.90 & 1.94 & 864 & 863 & 99.88 & Yes \\
\hline & FA & 0.60 & 0.67 & 864 & 852 & 98.61 & Yes \\
\hline & $\mathrm{ACO}$ & 0.53 & 0.62 & 864 & 862.2 & 99.76 & Yes \\
\hline \multirow{7}{*}{ 2.PS1 } & PSO & 1.60 & 1.80 & 512 & 498 & 97.27 & Yes \\
\hline & DFO & 0.59 & 0.75 & 512 & 509 & 99.41 & Yes \\
\hline & InC & 0.48 & 0.52 & 512 & 325 & 63.48 & No \\
\hline & Hybrid & 0.48 & 0.62 & 512 & 511.4 & 99.88 & Yes \\
\hline & CS & 1.60 & 1.78 & 512 & 506 & 98.83 & Yes \\
\hline & FA & 1.00 & 1.30 & 512 & 508 & 99.22 & Yes \\
\hline & $\mathrm{ACO}$ & 0.65 & 0.93 & 512 & 507 & 99.02 & No \\
\hline \multirow{7}{*}{ 3.PS2 } & PSO & 1.10 & 1.65 & 781 & 779 & 99.74 & Yes \\
\hline & DFO & 0.53 & 0.73 & 781 & 780 & 99.87 & Yes \\
\hline & InC & 0.22 & 0.22 & 781 & 712 & 91.17 & No \\
\hline & Hybrid & 0.20 & 0.89 & 781 & 780.4 & 99.92 & Yes \\
\hline & CS & 1.41 & 1.93 & 781 & 770.2 & 98.59 & Yes \\
\hline & FA & 1.01 & 1.42 & 781 & 769 & 98.46 & Yes \\
\hline & $\mathrm{ACO}$ & 0.31 & 0.35 & 781 & 768 & 98.33 & No \\
\hline \multirow{7}{*}{ 4.CPS } & PSO & 1.31 & 1.91 & 1250 & 1246 & 99.68 & Yes \\
\hline & DFO & 0.69 & 0.83 & 1250 & 1248 & 99.84 & Yes \\
\hline & InC & 0.39 & 0.45 & 1250 & 1094 & 87.52 & No \\
\hline & Hybrid & 0.41 & 0.75 & 1250 & 1249.8 & 99.98 & Yes \\
\hline & $\mathrm{CS}$ & 0.73 & 1.82 & 1250 & 1243 & 99.44 & No \\
\hline & FA & 0.52 & 0.80 & 1250 & 1157 & 92.56 & No \\
\hline & $\mathrm{ACO}$ & 0.59 & 1.40 & 1250 & 1247.1 & 99.76 & Yes \\
\hline
\end{tabular}

It is observed that the soft computing algorithms are robust, redundant, and highly adaptive. The Conventional InC conductance technique has the lowest convergence time for all weather conditions but it cannot track the GM for 2-3 cases of partial shading. This algorithm is very fast because of its gradient-based control and simplicity and has a low-cost control. InC techniques are only feasible for the UI condition where all the irradiance values of PV modules are the same and it can find GM. However, in the case of PS, this conventional technique has the lowest efficiency among all the other PSO, DFO, Hybrid, CS, FA, and ACO technique.

PS conditions are presented in cases 2 and 3. PSO method has taken more time to settle down at GM when compared with all other techniques. Due to the levy flight, the CS algorithm does not give efficient results at the transient's state. CS techniques have less oscillation as compared to the PSO method. So, as a result, there will be less power loss with enhanced performance. CPS dealt in case 4 and the proposed hybrid algorithm gives the effective results with the lowest settling and convergence time as compared to the other PSO, DFO, FA, CS, InC, and ACO techniques. In the case of CPS, PSO, and CS technique performance is compromised because they initialized the particles randomly.

For comparative analysis of all presented techniques, the DFO algorithm is included because it has effective unique characteristics like enemy avoidance, coherence, swarms closely spaced interaction. These DFO characteristics help to eliminate the oscillations and present optimized results of the PV energy systems. It is observed that the hybrid (InC-DFO) technique has a higher efficiency among all the comparing techniques and 
their output is oscillation-free for all-weather conditions. The hybrid technique tackles the steady-state and transient response successfully.

The result shows better performance compare to the results shown in the paper [45]. The settling time of PSO, DFO, InC, Hybrid, CS, FA, and ACO techniques are $1.80 \mathrm{~s}, 0.75 \mathrm{~s}$, $0.52 \mathrm{~s}, 0.62 \mathrm{~s}, 1.78 \mathrm{~s}, 1.30 \mathrm{~s}$, and $0.93 \mathrm{~s}$, respectively for PS1 condition and power tracked by proposed hybrid and all other DFO, CS, PSO, FA, InC, and ACO techniques are $511.4 \mathrm{~W}$, $509 \mathrm{~W}, 506 \mathrm{~W} .498 \mathrm{~W}, 325 \mathrm{~W}$, and $507 \mathrm{~W}$, respectively. The convergence time of the PS2 condition for PSO, DFO, InC, InC-DFO, CS, FA, and ACO techniques are $1.10 \mathrm{~s}, 0.53 \mathrm{~s}, 0.22 \mathrm{~s}$, $0.20 \mathrm{~s}, 1.41 \mathrm{~s}, 1.01 \mathrm{~s}, \& 0.31 \mathrm{~s}$, correspondingly. When comparing all the techniques it is observed that InC has the least convergence time. The settling time of ACO, FA, CS, hybrid, $\mathrm{InC}, \mathrm{DFO}$, and PSO are $0.35 \mathrm{~s}, 1.42 \mathrm{~s}, 1.93 \mathrm{~s}, 0.89 \mathrm{~s}, 0.22 \mathrm{~s}, 0.73 \mathrm{~s}$, and $1.65 \mathrm{~s}$, respectively. It is noted that the proposed technique presents the lowest settling time that decreases the power losses and enhances the efficiency of the PV energy systems. CS has the highest settling time that may result in loss of power. The Power of DFO, PSO, CS, FA, Inc, ACO, and hybrid techniques are $780 \mathrm{~W}, 779 \mathrm{~W}, 770.2 \mathrm{~W}, 769 \mathrm{~W}, 712 \mathrm{~W}, 768 \mathrm{~W}$, and $780.4 \mathrm{~W}$, correspondingly. It is noted that the proposed technique presents the lowest settling time that decreases the power losses and enhances the efficiency of the PV energy systems. In CPS conditions the convergence time of PSO, DFO, InC, hybrid, CS, FA, and ACO techniques are 1.31 s, 0.69 s, 0.39 s, 0.41 s, 0.73 s, 0.52 s, and 0.59 s, appropriately. Power of proposed hybrid and all previous $\mathrm{PSO}, \mathrm{DFO}, \mathrm{InC}$, hybrid, CS, FA, and ACO techniques are $1246 \mathrm{~W}, 1248 \mathrm{~W}, 1094 \mathrm{~W}, 1249.8 \mathrm{~W}, 1243 \mathrm{~W}, 1157 \mathrm{~W}$, and $1247.1 \mathrm{~W}$, respectively. The hybrid algorithm gives the highest power among all the techniques. From Table 3 , it is observed that it has the lowest convergence and settling time. The proposed algorithm tracks the GM efficiently and gives maximum efficiency of $99.93 \%, 99.88 \%, 99.92 \%$, and $99.98 \%$ in all operating conditions due to their two-stage running phenomena.

\subsection{Case 5. Field Atmospheric Data of Beijing}

Several factors are used to demonstrate the PV system's feasibility. Solar PV systems are commonly used in open regions where they are exposed to adverse weather conditions. Case 5 is all about a field study on a Chinese city, namely Beijing. Field atmospheric data are used to assess the proposed InC-DFO MPP searching method in real-world situations. Seasonal temperatures and irradiation levels are available from the Chinese meteorological agency (CMA) [46]. Total direct sunlight temperature and irradiance of two seasons are considered throughout the course of a day. The PV system consists of $4 \times 1$ arrays, each rated at 315.072 watts, for an installed capacity of 1260.288 watts. The data provides information on weather factors such as temperature and irradiance of the PV system. Transients of The 24-h have a 10-min resolution. Maximum power obtained during a 24-h period is used to determine the efficiency of the MPP tracking InC-DFO algorithm.

Table 4 shows the results of Case 5 . Summer is probably the most productive season in Beijing, having peak production power of $897.2 \mathrm{~W}$ between 10 a.m. and 3 p.m. In the fall, the highest hour of average power is $811 \mathrm{~W}$. Spring and winter are the least useful seasons in terms of power achievement. Beijing is located at 39.9042 North latitude and 116.4074 East latitude. According to the findings in all-weather situations, the InC-DFO algorithm gathers the most power. Figures 14 and 15 demonstrate a comprehensive examination of the InC-DFO algorithm collected power with, ACO, FA, DFO, InC, PSO, and CS in Beijing over the course of $24 \mathrm{~h}$ in the summer and spring. The results demonstrate that the proposed InC-DFO algorithm delivers better results and is more efficient. 


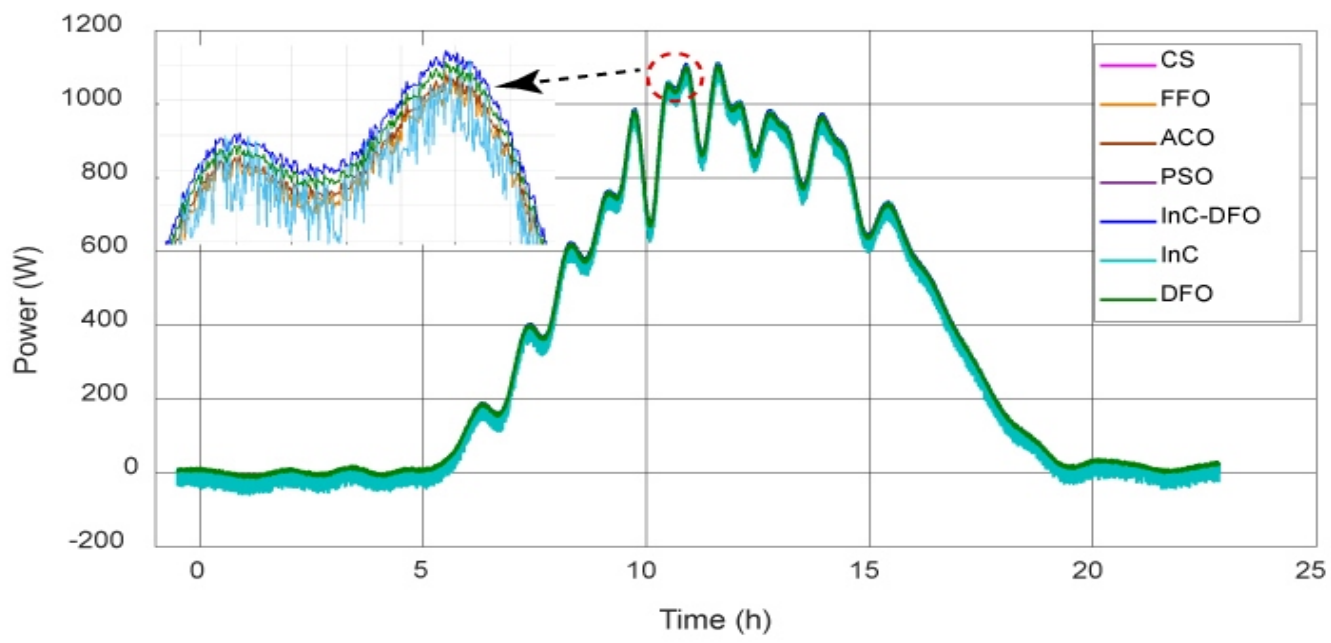

Figure 14. Power comparing of Spring in Beijing of InC-DFO algorithm with CS, FA, ACO, PSO, InC, and DFO.

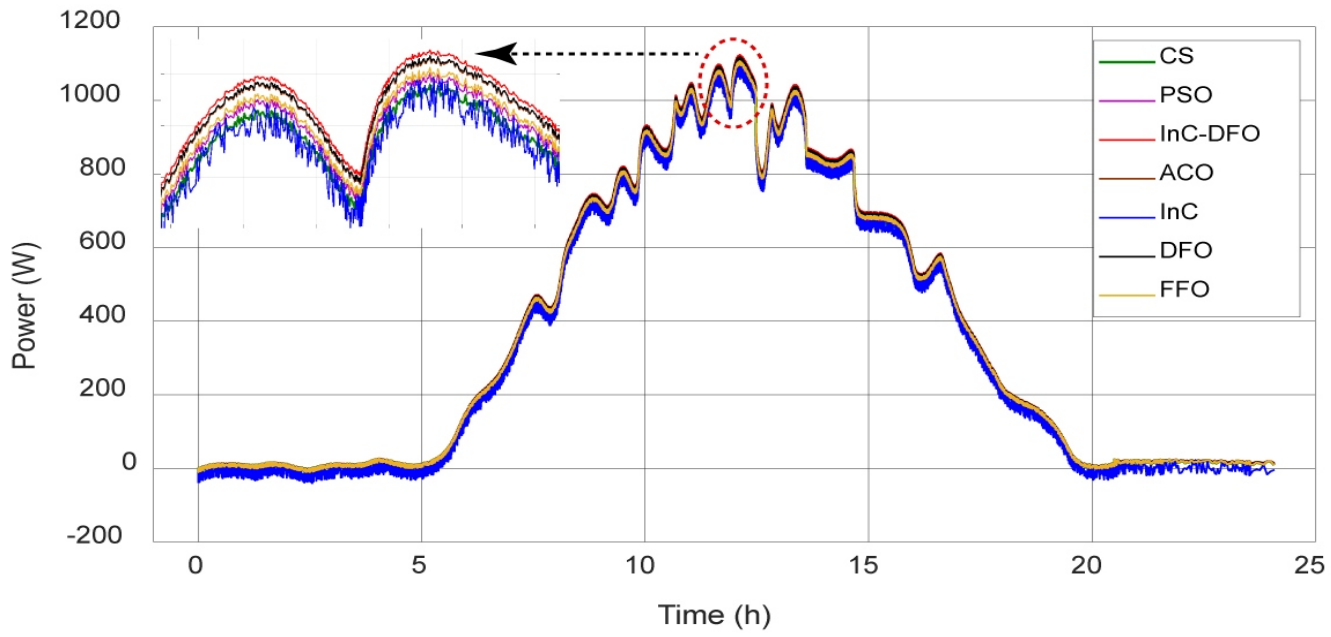

Figure 15. Power comparing of Summer in Beijing of InC-DFO algorithm with CS, FA, ACO, PSO, InC, and DFO.

Table 4. Results summary of case 5 field atmospheric data in Beijing City.

\begin{tabular}{llllllllll}
\hline Name of City & Season & Calculate & $\begin{array}{l}\text { InC- } \\
\text { DFO }\end{array}$ & CS & FA & ACO & PSO & InC & DFO \\
\hline Beijing & Summer & Power $_{\max }(W)$ & 1122 & 1098 & 1107 & 1109 & 1102 & 1093 & 1113 \\
\hline & Spring & Power $_{\max }(W)$ & 1105 & 1085 & 1089 & 1095 & 1087 & 1080 & 1098 \\
\hline
\end{tabular}

\section{Conclusions}

This paper elaborated a hybrid (InC-DFO) MPPT technique to harvest the maximum power of solar PV energy systems. Comparison of the proposed InC-DFO method is done with the six other already in use techniques such as PSO, DFO, FA, ACO, InC with variable step size, and CS MPPT technique. The comparison is tested for four cases from which one case is for UI, two cases for PS and one case is for CPS condition. After comparing the previous techniques with the proposed technique, the results (statistical data in Table 3 and analytical analysis show that the proposed hybrid technique outperforms convergence time, settling time, power, efficiency, and robustness. It has the lowest settling time of $0.75 \mathrm{~s}$ to find the GM, even in the case of CPS. InC-DFO technique gives the highest efficiency 
for all weather conditions like UI, PS, and CPS. This proposed technique saved the power losses because of the fast searching ability of a GM and reduced the settling time that may enhance the performance of the PV energy systems in a transient state. Moreover, ripples and overshoot is eliminated because of zero oscillation in the transient state. It is thus concluded that although the conventional techniques are suitable for uniform irradiance, they do not find GM in the case of partial shading. Similarly, they require less time for tracking but they are stuck on LM. On the other side, bio-inspired methods are complex and take more time in finding the MPP. The proposed hybrid technique is the combination of $\mathrm{InC}$ and $\mathrm{DFO}$, and it is used in two stages. In the first stage, the conventional InC technique with variable step size is adopted because of less convergence and settling time while in the second stage, a bio-inspired DFO technique is implemented for finding the GM quicker. The proposed technique outperforms the competition in terms of MPP monitoring and integration at the global MPP. The suggested MPPT technique efficiently achieves tracking time improvements of $10-29 \%$ and spontaneous oscillation reductions of more than $91 \%$. The hybrid MPPT technique provides faster maximum power point (MPP) monitoring, lower computational pressure, and increased performance.

Author Contributions: Conceptualization, S.S., M.Y.J. and M.H.J.; methodology, S.S., J.A., M.S. and A.U.R.; software, S.S., M.Y.J., A.U.R. and M.H.J.; validation, S.S., J.A., M.S. and J.-G.C.; formal analysis, S.S., M.Y.J. and M.H.J.; investigation, S.S., J.A., M.S. and J.-G.C.; resources, S.S., M.Y.J., A.U.R. and M.H.J.; data curation, S.S., J.A., M.S. and J.-G.C.; writing-original draft preparation, S.S., M.Y.J. and M.H.J.; writing—review and editing, S.S., J.A., M.S. and J.-G.C.; visualization, S.S., M.Y.J., A.U.R. and M.H.J.; supervision, J.A., M.S. and J.-G.C.; project administration, J.A. and M.S.; funding acquisition, J.-G.C. All authors have read and agreed to the published version of the manuscript.

Funding: This work was supported by the Basic Science Research Program through the National Research Foundation (NRF) of Korea funded by the Ministry of Education under Grant 2018R1D1A1B07048948.

Institutional Review Board Statement: Not applicable.

Informed Consent Statement: Not applicable.

Data Availability Statement: Not applicable.

Conflicts of Interest: The authors declare no conflict of interest.

\section{References}

1. Pourbehzadi, M.; Niknam, T.; Aghaei, J.; Mokryani, G.; Shafie-khah, M.; Catalão, J.P. Optimal operation of hybrid AC/DC microgrids under uncertainty of renewable energy resources: A comprehensive review. Int. J. Electr. Power Energy Syst. 2019, 109, 139-159. [CrossRef]

2. Kumar, N.; Nema, S.; Nema, R.K.; Verma, D. A state-of-the-art review on conventional, soft computing, and hybrid techniques for shading mitigation in photovoltaic applications. Int. Trans. Electr. Energy Syst. 2020, 30, e12420. [CrossRef]

3. Pachauri, R.; Singh, R.; Gehlot, A.; Samakaria, R.; Choudhury, S. Experimental analysis to extract maximum power from PV array reconfiguration under partial shading conditions. Eng. Sci. Technol. Int. J. 2019, 22, 109-130. [CrossRef]

4. Saravanan, S.; Babu, N.R. Maximum power point tracking algorithms for photovoltaic system-A review. Renew. Sustain. Energy Rev. 2016, 57, 192-204. [CrossRef]

5. Mao, M.; Cui, L.; Zhang, Q.; Guo, K.; Zhou, L.; Huang, H. Classification and summarization of solar photovoltaic MPPT techniques: A review based on traditional and intelligent control strategies. Energy Rep. 2020, 6, 1312-1327. [CrossRef]

6. Huang, Y.P.; Hsu, S.Y. A performance evaluation model of a high concentration photovoltaic module with a fractional open circuit voltage-based maximum power point tracking algorithm. Comput. Electr. Eng. 2016, 51, 331-342. [CrossRef]

7. Javed, M.Y.; Gulzar, M.M.; Rizvi, S.T.H.; Arif, A. A hybrid technique to harvest maximum power from PV systems under partial shading conditions. In Proceedings of the 2016 International Conference on Emerging Technologies (ICET), Islamabad, Pakistan, 18-19 October 2016; pp. 1-5.

8. Bhukya, M.N.; Kota, V.R. A quick and effective MPPT scheme for solar power generation during dynamic weather and partial shaded conditions. Eng. Sci. Technol. Int. J. 2019, 22, 869-884. [CrossRef]

9. Costanzo, L.; Vitelli, M. Resonant electromagnetic vibration harvesters applications: Optimization of P\&O MPPT technique parameters. In Proceedings of the 2018 Thirteenth International Conference on Ecological Vehicles and Renewable Energies (EVER), Monte Carlo, Monaco, 10-12 April 2018; pp. 1-8.

10. Kermadi, M.; Salam, Z.; Ahmed, J.; Berkouk, E.M. An effective hybrid maximum power point tracker of photovoltaic arrays for complex partial shading conditions. IEEE Trans. Ind. Electron. 2018, 66, 6990-7000. [CrossRef] 
11. Ahmed, J.; Salam, Z. An improved method to predict the position of maximum power point during partial shading for PV arrays. IEEE Trans. Ind. Inform. 2015, 11, 1378-1387. [CrossRef]

12. Chin, V.J.; Salam, Z. A new three-point-based approach for the parameter extraction of photovoltaic cells. Appl. Energy 2019, 237, 519-533. [CrossRef]

13. Kumar, M.S.; Manoharan, P.; Ramachandran, R. Modelling and simulation of ANFIS-based MPPT for PV system with modified SEPIC converter. Int. J. Bus. Intell. Data Min. 2019, 15, 255-272. [CrossRef]

14. Kayri, I.; Gencoglu, M.T. Predicting power production from a photovoltaic panel through artificial neural networks using atmospheric indicators. Neural Comput. Appl. 2019, 31, 3573-3586. [CrossRef]

15. Hafendi, M.A.; Abd Wahab, H. Optimization of Stand-Alone Polycrystalline Photovoltaic Array System by Implementing Fuzzy Logic and Perturbation and Observation Maximum Power Point Tracking Controller. Commun. Comput. Appl. Math. 2019, 1, 34-40.

16. Priyadarshi, N.; Sharma, A.K.; Bhoi, A.K.; Ahmad, S.; Azam, A.; Priyam, S. MATLAB/Simulink based fault analysis of PV grid with intelligent fuzzy logic control MPPT. Int. J. Eng. Technol. 2018, 7, 198-204. [CrossRef]

17. Khabou, H.; Souissi, M.; Aitouche, A. MPPT implementation on boost converter by using T-S fuzzy method. Math. Comput. Simul. 2020, 167, 119-134. [CrossRef]

18. Farajdadian, S.; Hosseini, S.H. Design of an optimal fuzzy controller to obtain maximum power in solar power generation system Sol. Energy 2019, 182, 161-178. [CrossRef]

19. Hong, Y.Y.; Beltran, A.A., Jr.; Paglinawan, A.C. A robust design of maximum power point tracking using Taguchi method for stand-alone PV system. Appl. Energy 2018, 211, 50-63. [CrossRef]

20. Ram, J.P.; Babu, T.S.; Rajasekar, N. A comprehensive review on solar PV maximum power point tracking techniques. Renew. Sustain. Energy Rev. 2017, 67, 826-847. [CrossRef]

21. Shahdadi, A.; Khajeh, A.; Barakati, S.M. A new slip surface sliding mode controller to implement MPPT method in photovoltaic system. In Proceedings of the 2018 9th Annual Power Electronics, Drives Systems and Technologies Conference (PEDSTC), Tehran, Iran, 13-15 February 2018; pp. 212-217.

22. Oliveira-Pinto, S.; Stokkermans, J. Assessment of the potential of different floating solar technologies-overview and analysis of different case studies. Energy Convers. Manag. 2020, 211, 112747. [CrossRef]

23. Ram, J.P.; Pillai, D.S.; Ghias, A.M.; Rajasekar, N. Performance enhancement of solar PV systems applying P\&O assisted Flower Pollination Algorithm (FPA). Sol. Energy 2020, 199, 214-229.

24. Pei, T.; Hao, X.; Gu, Q. A novel global maximum power point tracking strategy based on modified flower pollination algorithm for photovoltaic systems under non-uniform irradiation and temperature conditions. Energies 2018, 11, 2708. [CrossRef]

25. Kostenko, V.; Seleznev, L. Random Search Algorithm with Self-Learning for Neural Network Training. Opt. Mem. Neural Netw. 2021, 30, 180-186. [CrossRef]

26. Hemalatha, C.; Rajkumar, M.V.; Krishnan, G.V. Simulation and Analysis for MPPT Control with Modified firefly algorithm for photovoltaic system. Int. J. Innov. Stud. Sci. Eng. Technol. 2016, 2, 48-52.

27. Mishra, J.; Das, S.; Kumar, D.; Pattnaik, M. A novel auto-tuned adaptive frequency and adaptive step-size incremental conductance MPPT algorithm for photovoltaic system. Int. Trans. Electr. Energy Syst. 2021, 31, 1-14. [CrossRef]

28. Elbarbary, Z.M.S.; Alranini, M.A. Review of maximum power point tracking algorithms of PV system. Front. Eng. Built Environ. 2021, 1, 68-80. [CrossRef]

29. Mahdi, A.; Mahamad, A.; Saon, S.; Tuwoso, T.; Elmunsyah, H.; Mudjanarko, S. Maximum power point tracking using perturb and observe, fuzzy logic and ANFIS. SN Appl. Sci. 2020, 2, 89. [CrossRef]

30. Demircan, C.; Keçebaş, A.; Bayrakçı, H.C. Artificial Bee Colony-Based GMPPT for Non-homogeneous Operating Conditions in a Bifacial CPVT System. In Modern Maximum Power Point Tracking Techniques for Photovoltaic Energy Systems; Springer: Cham, Switzerland, 2020; pp. 331-353. [CrossRef]

31. Titri, S.; Larbes, C.; Toumi, K.Y.; Benatchba, K. A new MPPT controller based on the Ant colony optimization algorithm for Photovoltaic systems under partial shading conditions. Appl. Soft Comput. 2017, 58, 465-479. [CrossRef]

32. Javed, M.Y.; Ling, Q.; Rahman, H.; Saleem, Y.; Gulzar, M.M. Design and implementation of a single-phase multilevel cascaded inverter for PV system. 2016 International Conference on Smart Grid and Clean Energy Technologies (ICSGCE), Chengdu, China, 19-22 October 2016; pp. 201-206.

33. Ibrahim, A.E.; Nor, N.M.; Nawi, I.B.M.; Mohd, F.R.; Mohd, K.N. Genetic algorithm to improve power output of photovoltaic system under partial shaded condition. Int. J. Power Electron. Drive Syst. 2019, 10, 2182. [CrossRef]

34. Tajuddin, M.; Azmi, A.; Ayob, S.; Sutikno, T. Differential Evolution Based Solar Photovoltaic Array Reconfiguration Algorithm for Optimal Energy Extraction during Partial Shading Condition. Int. J. Power Electron. Drive Syst. 2018, 9, 1397.

35. Suhardi, D.; Syafaah, L.; Irfan, M.; Yusuf, M.; Effendy, M.; Pakaya, I. Improvement of maximum power point tracking (MPPT) efficiency using grey wolf optimization (GWO) algorithm in photovoltaic (PV) system. In IOP Conference Series: Materials Science and Engineering, Proceedings of the 2nd International Conference on Engineering and Applied Technology, Aceh, Indonesia, 9-10 October 2019; IOP Publishing: Bristol, UK, 2019; Volume 674, pp. 1-11. [CrossRef]

36. Lin, Z.; Wang, J.; Fang, Z.; Hu, M.; Cai, C.; Zhang, J. Accurate maximum power tracking of wireless power transfer system based on simulated annealing algorithm. IEEE Access 2018, 6, 60881-60890. [CrossRef] 
37. Yiğit, S.; YAĞCI, M. Modelling of Maximum Power Point Tracking of Photovoltaic Module Using Incremental Conductance Method. Avrupa Bilim Teknol. Derg. 2020, 1-5. [CrossRef]

38. Belkaid, A.; Colak, I.; Kayisli, K.; Bayindir, R. Design and implementation of a cuk converter controlled by a direct duty cycle INC-MPPT in PV battery system. Int. J. Smart Grid-ijSmartGrid 2019, 3, 19-25.

39. Costanzo, L.; Vitelli, M. A novel MPPT technique for single stage grid-connected PV systems: T4S. Energies 2019, $12,4501$. [CrossRef]

40. Mirjalili, S. Dragonfly algorithm: A new meta-heuristic optimization technique for solving single-objective, discrete, and multi-objective problems. Neural Comput. Appl. 2016, 27, 1053-1073. [CrossRef]

41. Kobayashi, K.; Takano, I.; Sawada, Y. A study of a two stage maximum power point tracking control of a photovoltaic system under partially shaded insolation conditions. Sol. Energy Mater. Sol. Cells 2006, 90, 2975-2988. [CrossRef]

42. Ahmed, J.; Salam, Z. An accurate method for MPPT to detect the partial shading occurrence in a PV system. IEEE Trans. Ind. Inform. 2017, 13, 2151-2161. [CrossRef]

43. Javed, M.Y.; Murtaza, A.F.; Ling, Q.; Qamar, S.; Gulzar, M.M. A novel MPPT design using generalized pattern search for partial shading. Energy Build. 2016, 133, 59-69. [CrossRef]

44. Miyatake, M.; Veerachary, M.; Toriumi, F.; Fujii, N.; Ko, H. Maximum power point tracking of multiple photovoltaic arrays: A PSO approach. IEEE Trans. Aerosp. Electron. Syst. 2011, 47, 367-380. [CrossRef]

45. Chandrasekaran, K.; Sankar, S.; Banumalar, K. Partial shading detection for PV arrays in a maximum power tracking system using the sine-cosine algorithm. Energy Sustain. Dev. 2020, 55, 105-121. [CrossRef]

46. Zhang, X.; Li, S.; He, T.; Yang, B.; Yu, T.; Li, H.; Jiang, L.; Sun, L. Memetic reinforcement learning based maximum power point tracking design for PV systems under partial shading condition. Energy 2019, 174, 1079-1090. [CrossRef] 